\title{
The GJU Website Development Process and Best Practices
}

\author{
Feras Al-Hawari, German Jordanian University, Jordan \\ iD https://orcid.org/0000-0001-6948-3336 \\ Mai Al-Zu'bi, German Jordanian University, Jordan \\ Hala Barham, German Jordanian University, Jordan \\ Wael Sararhah, German Jordanian University, Jordan
}

\begin{abstract}
This paper introduces a website development process comprised of six phases: requirements, content, design, development, launch, and maintenance. In this context, a website is considered the primary marketing channel for a university and has different characteristics than web-portals. In the content phase, a flat content structure with fielded content types has been defined to make the website contentrich and intuitive to navigate. In the design phase, reusable page templates and engaging UI components were proposed to improve website appearance, usability, and responsiveness. In the development phase, the development framework, technology stack, and development steps to build non-interactive websites have been suggested. Best practices to test, secure, and monitor the website before launching it were also covered in the launch phase. Hosting a website in-house requires addressing issues like quality assurance and system administration in the maintenance phase. Yet, the analytics reports and survey results showed that the suggested process enabled producing a high-quality website.
\end{abstract}

\section{KEYWORDS}

Best Practices, Content Management System, Content Structure, Drupal, Graphical Design, Website Development Process, Website Security

\section{INTRODUCTION}

Affordable and widespread internet access has made the World Wide Web a significant source of information. Therefore, building a strong online identity has become a key marketing mechanism for any institution. The web presence of an institution can be established through an official website, social media accounts, and other related mediums. Such channels must be meticulously designed, structured, implemented, and managed in order to maintain a good business reputation and catch the attention of many visitors. Based on that, this paper focuses on the best practices to design and develop a high-quality website that is considered a main instrument to strengthen the online identity of the German Jordanian University (GJU). 
The GJU website ("GJU Website,") is regarded the first point of contact for many university stakeholders such as students, faculty, staff, parents, alumni, partners, providers, and employers. Therefore, it should make a strong first impression to attract talented students and staff to GJU, as well as engage other visitors. To accomplish the aforementioned objective, the website must have the following quality attributes: nice appearance, modern design, well defined structure, up to date, content rich, easy to use, consistent, fast, and highly available. Furthermore, it should reflect the university brand, vision, mission, values, and objectives. In addition, it needs to effectively promote the offered degrees and programs, in addition to the ongoing research.

Accordingly, the following measures are required to develop a GJU website (or any similar university website) that meets the desired quality attributes:

- Introducing a suitable website development process.

- Defining proper content types and structure to make university websites content-rich, easy to use, and intuitive to navigate.

- Suggesting graphic design guidelines to enhance the appearance, navigation, usability, responsiveness, and functionality of university websites.

- Proposing a development framework and technology stack to build simple and non-interactive websites.

- Demonstrating the website development steps needed to construct a website using a Content Management System (CMS) such as Drupal (“Drupal - Open Source CMS,").

- Discussing the adopted tests to verify the website operation, quality, and scalability.

- Recommending the needed measures to secure the open-source CMS and the stack it runs on.

- Identifying the tasks to administer the host machine, web application, and CMS.

- Utilizing google analytics and user survey results to evaluate the website quality attributes.

The rest of the paper is organized as follows. In section 2, the novelty of this work is highlighted. In section 3, a suitable website development process is introduced. In section 4, the proper university website content types and structure are proposed. In section 5, the website design guidelines are suggested. In section 6, the website development framework and steps are illustrated. In section 7 , the needed operations to launch a website are discussed. In section 8 , the best practices during the website maintenance phase are explored. In section 9, google analytics and user-survey based methods are utilized to evaluate the quality-attributes of the GJU website. Finally, summary and conclusion are provided in section 10 .

\section{PAPER NOVELTY}

It is important to emphasize that the main novelties of this paper are related to the best practices to design and develop a university website rather than a web portal (e.g., student information system (Al-Hawari, Alufeishat, Alshawabkeh, Barham, \& Habahbeh, 2017), help desk system (Al-Hawari \& Barham, 2019), and accounting information system (Al-Hawari, 2017)). In that regard, a website is distinguished from a web portal by the following:

- It focuses more on content.

- It does not require a visitor to login (i.e., anyone can see the website content).

- It does not allow a visitor to change content (i.e., non-interactive).

- It requires multiple collaborators (i.e., content editors) to manage related content. 


\subsection{Novel Website Development Process}

The website development process was broadly investigated in the academia (e.g., (Friedlein, 2001; Kelo, 2017; Kumari \& Nandal, 2017; Lynch \& Horton, 2016; Yahaya, Ibrahim, \& Deraman, 2017)) and industry (e.g., (Group, 2020; Luke, 2011; Simplesquare, 2017)). Nevertheless, the proposed processes mainly differed in the number of phases and names of the phases as shown in Table 1 . Accordingly, a development team is required to decide which of those processes is more suitable to develop their website. Based on that, one of the main contributions of this work is related to naming and determining the required phases to develop a university website such that each phase addresses a separate concern (i.e., based on the Separation of Concerns (SoC) design principle). Based on the processes in Table 1, it was obvious that some researchers inaccurately considered the project management process as a phase (e.g., the Brief phase in (Group, 2020) and the Project Management phase in (Lynch \& Horton, 2016)) in the website development process. Others like (Friedlein, 2001; Kelo, 2017; Lynch \& Horton, 2016) reduced the number of phases to four, which contradicts the SoC principle because several separate phases have been merged into a single phase in those processes. On the other hand, others have introduced extra phases in the process by splitting some tasks that belong to the same phase into different phases (e.g., the Analysis and Specification phases in (Kumari $\&$ Nandal, 2017) that usually belong to the Requirements phase). After analysing the processes in Table 1, a novel website development process (see Figure 1 and section 3 ) that is comprised of six phases is proposed:

1. Requirements Phase: This phase is important as it deals with defining the website's functional and content requirements.

2. Content Phase: This phase has to be emphasized as websites are mainly built around content.

3. Design Phase: It is kept as it is included explicitly or implicitly in all processes in Table 1.

4. Development Phase: It is kept as it is found explicitly or implicitly in all processes in Table 1.

5. Launch Phase: This phase has to be separate because it includes several important steps.

6. Maintenance Phase: It is kept as it is included one way or another in all processes in Table 1.

Noting that some phases in Table 1 were not included in the proposed website development process due to one of the following reasons:

1. Elimination: The Project Management, Planning, and Brief phases were eliminated as they belong to the project management process rather than the website development process.

2. Renaming: The Idea phase was renamed to Requirements phase. The Site Construction and Coding phases were renamed to Development phase. Further, the Post Launch phase was renamed to Maintenance phase.

3. Inclusion: The Final Integration and Promotion phases are actually steps in the Launch phase. The Initial Contact and Specification phases are only steps in the Requirements phase. Whereas, different Testing types may occur in the Development, Launch, and Maintenance phases.

4. Splitting: For example, the Production phase has been broken into the Content, Design, Development, and Launch phases to comply with the SoC principle.

\subsection{Novel Practices in the Phases of the Website Development Process}

The best practices (i.e., suggested steps) that were applied in the various phases of the proposed website development process are listed in the GJU column in Table 2. Besides, each row in the table shows whether the respective step was used (i.e., $\checkmark$ ) or not (i.e., $\mathbf{x}$ ) in the competing website development processes that were chosen from the academia and industry for comparison purposes. Accordingly, the advantages of the proposed approach in this paper can be summarized as follows: 
Table 1. Comparison between various website development processes

\begin{tabular}{|c|c|c|c|c|c|c|c|c|}
\hline $\begin{array}{l}\text { (Group, } \\
\text { 2020) }\end{array}$ & $\begin{array}{l}\text { (Rab, } \\
\text { 2018) }\end{array}$ & $\begin{array}{l}\text { (Kelo, } \\
\text { 2017) }\end{array}$ & $\begin{array}{c}\text { (Kumari } \\
\text { \& Nandal, } \\
\text { 2017) }\end{array}$ & $\begin{array}{c}\text { (Yahaya et al., } \\
\text { 2017) }\end{array}$ & $\begin{array}{c}\text { (Simplesquare, } \\
\text { 2017) }\end{array}$ & $\begin{array}{c}\text { (Lynch \& } \\
\text { Horton, } \\
\text { 2016) }\end{array}$ & $\begin{array}{l}\text { (Luke, } \\
\text { 2011) }\end{array}$ & $\begin{array}{l}\text { (Friedlein, } \\
\text { 2001) }\end{array}$ \\
\hline Brief & Idea & Planning & Analysis & Requirements & Initial Contact & $\begin{array}{l}\text { Project } \\
\text { Management }\end{array}$ & Planning & Reproduction \\
\hline Planning & Design & Devel. & Specification & Design & Planning & $\begin{array}{l}\text { Information } \\
\text { Design }\end{array}$ & Design & Production \\
\hline Design & Coding & Launch & Design & Implementation & Content & $\begin{array}{l}\text { Site } \\
\text { Construction }\end{array}$ & Devel. & Maintenance \\
\hline Development & Test & Maint. & Content & Operation & Design & $\begin{array}{l}\text { Final } \\
\text { Integration }\end{array}$ & Launch & Evaluation \\
\hline Launch & Launch & & Coding & & Devel. & & $\begin{array}{l}\text { Post } \\
\text { Launch }\end{array}$ & \\
\hline \multirow[t]{3}{*}{ Maintenance } & & & Testing & & Launch & & & \\
\hline & & & Promotion & & & & & \\
\hline & & & Maintenance & & & & & \\
\hline
\end{tabular}

Figure 1. The six phases in the proposed website development process

Project Management Process

Website Development Process
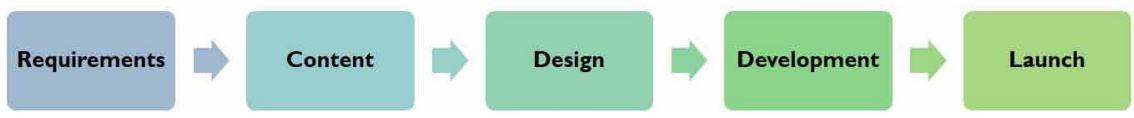

Maintenance

1. None of the related processes emphasized the importance of defining fielded content types given that such types enable dynamic display, filtering, and grouping of information based on the values of the desired fields (see section 4). Also, none of them pointed out the fact that content should be centered on the core university strengths in order to entrench the university brand, mission, and message in most the website pages.

2. Although all the related processes discussed the significance of content and its structure especially when it can affect a student decision to consider and attend a certain university (Bernier, Barchéin, Cañas, Gómez-Valenzuela, \& Merelo, 2002; Ford, 2011; Gehrke \& Turban, 1999; Owoyele, 2017; Schimmel, Motley, Racic, Marco, \& Eschenfelder, 2010; Suwawi, Darwiyanto, \& Rochmani, 2015; Taylor, 2011; Tubin \& Klein, 2007), but none of them highlighted the importance of keeping the content structure tree flat (i.e., with few levels) in order to minimize the number of needed clicks to reach any desired page. Further, none of them classified the content into four types (i.e., academic, administrative, about the university, and media) as proposed in this paper (see section 4). Noting that the work in (Ojino, Mich, Ogao, \& Karume, 2013; Zhang, 2017) also discussed university website content types, but did not propose a development process.

3. As far as usability, the flat content structure and the well-designed templates enabled reaching the major website content in either 1 click or 2 clicks from the front page (see Table 3), which makes the website easy to use and intuitive to navigate. Also, fewer researchers focused on the 
Table 2. The main practices in the different phases of the website development process

\begin{tabular}{|c|c|c|c|c|c|c|c|c|c|c|}
\hline & & & \multicolumn{7}{|c|}{ Other Researchers } & \multirow[b]{2}{*}{$\begin{array}{c}\text { Covered } \\
\text { by } \\
\text { Others }\end{array}$} \\
\hline Phase & Practice & GJU & $\begin{array}{l}\text { (Group, } \\
\text { 2020) }\end{array}$ & $\begin{array}{l}\text { (Rab, } \\
\text { 2018) }\end{array}$ & $\begin{array}{l}\text { (Kelo, } \\
\text { 2017) }\end{array}$ & $\begin{array}{c}\text { (Kumari } \\
\text { \& Nandal, } \\
\text { 2017) }\end{array}$ & $\begin{array}{l}\text { (Yahaya } \\
\text { et al., } \\
\text { 2017) }\end{array}$ & $\begin{array}{l}\text { (Luke, } \\
\text { 2011) }\end{array}$ & $\begin{array}{l}\text { (Friedlein, } \\
\text { 2001) }\end{array}$ & \\
\hline \multirow{2}{*}{ Requirements } & Brainstorming & $\checkmark$ & $\checkmark$ & $\checkmark$ & $\checkmark$ & $\checkmark$ & $\checkmark$ & $\checkmark$ & $\checkmark$ & 7 \\
\hline & Specifications & $\checkmark$ & $\checkmark$ & $\checkmark$ & $\checkmark$ & $\checkmark$ & $\checkmark$ & $\checkmark$ & $\checkmark$ & 7 \\
\hline \multirow{3}{*}{ Content } & Structure & $\checkmark$ & $\checkmark$ & $\checkmark$ & $\checkmark$ & $\checkmark$ & $\checkmark$ & $\checkmark$ & $\checkmark$ & 7 \\
\hline & $\begin{array}{l}\text { Fielded Content } \\
\text { Types }\end{array}$ & $\checkmark$ & $x$ & $x$ & $x$ & $x$ & $x$ & $x$ & $x$ & $\mathbf{0}$ \\
\hline & $\begin{array}{l}\text { Promote Core } \\
\text { Strengths }\end{array}$ & $\checkmark$ & $x$ & $x$ & $x$ & $x$ & $x$ & $x$ & $x$ & $\mathbf{0}$ \\
\hline \multirow{4}{*}{ Design } & Templates & $\checkmark$ & $\checkmark$ & $\checkmark$ & $x$ & $\checkmark$ & $\checkmark$ & $\checkmark$ & $x$ & 5 \\
\hline & Features & $\checkmark$ & $\checkmark$ & $\checkmark$ & $\checkmark$ & $\checkmark$ & $\checkmark$ & $\checkmark$ & $\checkmark$ & 7 \\
\hline & Usability & $\checkmark$ & $\checkmark$ & $x$ & $\checkmark$ & $x$ & $\checkmark$ & $x$ & $\checkmark$ & 4 \\
\hline & Responsiveness & $\checkmark$ & $\checkmark$ & $\checkmark$ & $x$ & $x$ & $x$ & $\checkmark$ & $x$ & 3 \\
\hline \multirow{3}{*}{ Development } & $\begin{array}{l}\text { Development } \\
\text { Framework }\end{array}$ & $\checkmark$ & $\checkmark$ & $\checkmark$ & $x$ & $\checkmark$ & $\checkmark$ & $\checkmark$ & $\checkmark$ & 6 \\
\hline & $\begin{array}{l}\text { Development } \\
\text { Steps }\end{array}$ & $\checkmark$ & $x$ & $x$ & $x$ & $x$ & $x$ & $x$ & $x$ & $\mathbf{0}$ \\
\hline & Content Editing & $\checkmark$ & $\checkmark$ & $x$ & $\checkmark$ & $\checkmark$ & $x$ & $x$ & $\checkmark$ & 4 \\
\hline \multirow{7}{*}{ Launch } & Testing & $\checkmark$ & $\checkmark$ & $x$ & $\checkmark$ & $\checkmark$ & $\checkmark$ & $\checkmark$ & $\checkmark$ & 6 \\
\hline & Security Steps & $\checkmark$ & $x$ & $x$ & $x$ & $x$ & $x$ & $x$ & $x$ & $\mathbf{0}$ \\
\hline & Documentation & $\checkmark$ & $\checkmark$ & $x$ & $x$ & $x$ & $x$ & $\checkmark$ & $\checkmark$ & 3 \\
\hline & User Accounts & $\checkmark$ & $x$ & $\checkmark$ & $x$ & $x$ & $x$ & $x$ & $x$ & 1 \\
\hline & Training & $\checkmark$ & $\checkmark$ & $x$ & $\checkmark$ & $x$ & $\checkmark$ & $x$ & $\checkmark$ & 4 \\
\hline & Analytics & $\checkmark$ & $\checkmark$ & $x$ & $\checkmark$ & $x$ & $x$ & $x$ & $\checkmark$ & 3 \\
\hline & Deployment & $\checkmark$ & $\checkmark$ & $\checkmark$ & $\checkmark$ & $\checkmark$ & $\checkmark$ & $\checkmark$ & $\checkmark$ & 7 \\
\hline \multirow{4}{*}{ Maintenance } & QA & $\checkmark$ & $\checkmark$ & $x$ & $\checkmark$ & $x$ & $x$ & $x$ & $\checkmark$ & 3 \\
\hline & Updates & $\checkmark$ & $\checkmark$ & $x$ & $\checkmark$ & $\checkmark$ & $x$ & $x$ & $\checkmark$ & 4 \\
\hline & Administration & $\checkmark$ & $x$ & $x$ & $x$ & $x$ & $x$ & $x$ & $x$ & $\mathbf{0}$ \\
\hline & Training & $\checkmark$ & $\checkmark$ & $x$ & $x$ & $x$ & $\checkmark$ & $x$ & $x$ & 2 \\
\hline
\end{tabular}

importance of having responsive website in order to offer the viewer easy navigation and simple reading on different screen sizes.

4. Most processes addressed development framework choices to build websites. In this paper, it was recommended that a CMS is more suitable than a PHP (Hypertext Pre-processor), JSP (Java Server Pages), JSF (Java Server Faces), or ASP (Active Server Pages) framework for website development because it enables building a simple website (i.e., it does not require complex workflows and functionality) via an easy to use administrative dashboard without the need for any advanced PHP, Java, or C\# programming skills. Also, the CMS allows defining user roles and assigning permissions to roles via simple screens. Besides, it supports many custom modules to easily add rich UI components (i.e., menus, slideshows, filters, forms, maps, etc.) to the web pages. Not to mention, when the control behavior of the application is simple and a CMS is used to develop a website, there is no need to use model-driven languages (Rossi, Urbieta, Distante, Rivero, \& Firmenich, 2016) like IFML (Interaction Flow Modelling Language) ("IFML: The 
Interaction Flow Modeling ") and WebML (Web Modelling Language) ("The Web Modeling Language (WebML),") to aid in the code generation of the website. Although, entity-relationship (ER) and class diagrams ("UWE: UML-based Web Engineering,") can help in the design and documentation of the content types and structure.

5. None of the related work discussed how to use a CMS like Drupal to develop the templates, develop the CSS classes, define fielded content types, associate a content type with other types, and enter the content (see section 6).

6. None of the related work specified the needed steps to secure the website ahead of its launch. In subsection 7.2, the important measures to secure the website host, web server, database management system, and content management system were proposed.

7. Not all researchers highlighted the importance of establishing user accounts (i.e., for administrators and content editors), training the content editors to use the CMS, and releasing all the required documentation, and linking the website to analytics tools in the Launch phase.

8. Most researchers mentioned updating the content in the maintenance phase. But, few of them realized the importance of offering further training to content editors (i.e., new and previous editors) on using the CMS and abiding by the website quality standards.

9. None of the other researchers recognized the need for various administration tasks in the maintenance phase such as system updates (e.g., updating/upgrading the OS, web server, and CMS), data backups (e.g., website files and database dumps), and user accounts (i.e., adding accounts, deactivating accounts, defining roles, and setting passwords).

\section{WEBSITE DEVELOPMENT PROCESS}

As discussed previously the phases that typically belong to the project management process were not included in the proposed website development process. In that regard, a project management process that is based on the systems engineering basic profile in the ISO/IEC 29110 series (Laporte, O'Connor, \& Paucar, 2015) is suitable to manage website related projects. Such process is interrelated with the website development process (see Figure 1) and addresses aspects like project planning (e.g., scope, resources, tasks, timeline, budget, etc.), progress, review, versioning, and risks. Whereas, the proposed software development process is comprised of the following six phases:

1. Requirements Phase: The website objectives, audience, content, services, and features are identified in this phase. In this particular project, a website committee that is led by the IT director and includes representatives from all related schools and departments was formed to specify, prioritize, and approve the website requirements. The ratified requirements were then passed to the website development team to proceed with the other development phases.

2. Content Phase: This phase is discussed in section 4 and copes with defining the content structure, types, and fields. The content structure is designed to be flat to allow accessing any content in a few clicks. The content types and fields are determined based on their relevance to the university's core strengths, vision, and message.

3. Design Phase: This phase is discussed in section 5 and addresses website design aspects related to templates, functionality, usability, and responsiveness. Few reusable templates are needed to control the layout (e.g., regions, header, footer, etc.) and style (e.g., background, font, color, logos, etc.) of the various website pages. The needed UI components (e.g., menus, tables, and slideshows) to support the website functionality are selected based on their ability to emphasize content, make pages attractive, and make navigation intuitive. The website should also be responsive to offer the viewer easy navigation and simple reading on different screen sizes.

4. Development Phase: This phase is discussed in section 6 and deals with the development framework (i.e., the used CMS like Drupal), implementation details (i.e., developing the cascaded 
style sheets, page templates, regions, content types, content groups, external plugins, PHP scripts, HTML files, etc.), and content editing (i.e., entering website text, images, videos, files, etc.).

5. Launch Phase: This phase is discussed in section 7 and handles issues such as testing (i.e., website unit, functional, usability, and stress testing), security (i.e., security of the host server, web server, CMS, and user accounts), user accounts (i.e., the management of the CMS accounts for the website administrators and content editors), training (i.e., training the content editors), documentation (e.g., CMS user guide, development guide, security guide, etc.), analytics (i.e., activating analytics tools to monitor website statistics), and deployment (i.e., official launch and promotion of the website).

6. Maintenance Phase: This phase in discussed in section 8 to cover website post-launch related matters such as quality assurance (QA), updates (e.g., adding new pages, editing content, defining new content types), administration (i.e., administering the CMS, Apache, database, and server), and training (i.e., frequent training of content editors).

\section{CONTENT PHASE}

A very important aspect to determine when building a website is its content because it is considered the essence of the website and thus the whole website should be built around content and not vice versa. Furthermore, the content structure, quality, and size as well as relevance to the GJU brand and message need to be thoroughly considered due to their positive effect on the website's user experience and rank in the search engines (e.g., Google) results pages (i.e., rankings in Search Engine Optimization (SEO) (Amrahov, 2016; Bin, Bingyun, Peishun, \& Xiaoqing, 2018)).

Accordingly, suitable content types are used in the construction of the website to highlight the GJU core strengths shown in Figure 2 and hence attract more talents to GJU. In that respect, GJU

Figure 2. The core strengths of GJU

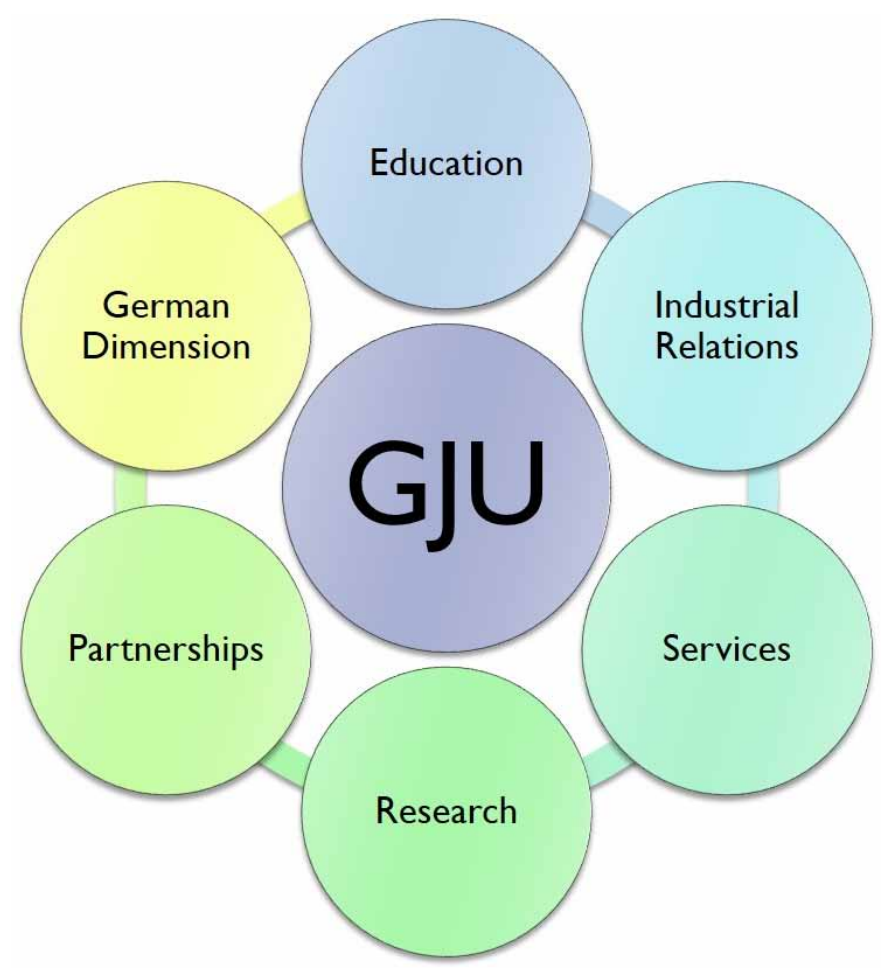


is well known for its high-quality practice-oriented education, applied research, and services (e.g., community, students, alumni, and staff services). Specifically, it has a German dimension that promotes links between Jordan and Germany in order to take advantage of the best educational practices in both countries. In that regard, all GJU undergraduate students spend their fourth year in Germany (i.e., German year) during which they take a semester in one of the German partner universities and spend another semester doing a practical internship in one of the German partner companies or organizations. The German Language Center (GLU) at GJU also offers mandatory German language courses to the students to prepare them for the German year. On the other hand, German and EU students also come to Jordan to spend a semester or more in GJU. Similarly, a trans-national academic and administrative staff exchange also takes place.

Yet, the GJU website is developed using a CMS and thus the majority of the pages are dynamically generated. Therefore, the structure of the content and the associations amongst the related content types are meticulously determined as they have a direct effect on the design and usability of the website. Particularly, the content structure tree is not very deep in order to minimize the number of needed clicks to reach a desired page. Moreover, the correct content types associations are established to allow defining an associated content once and then reusing it in many related pages. In addition, fielded content types are used to enable dynamic display, filtering, and grouping of information based on the values of the desired fields. Not to mention, English is the official language of the website content in order to support the internationalization vision of GJU, although few pages are edited in either the German or Arabic language as appropriate.

Suitably, the majority of the website content is classified according to the academic and administrative organizational structure of GJU as shown in Figure 3. At the same time, some content is also elevated to the highest level in case it is directly related to a core GJU strength or message. Moreover, the content and layout of any two pages with identical types should be similar in order to maintain the website consistency and offer a pleasant user experience. Appropriately, the core content types that have been defined to build the website pages are discussed in the following subsections.

Figure 3. The basic academic and administrative content types
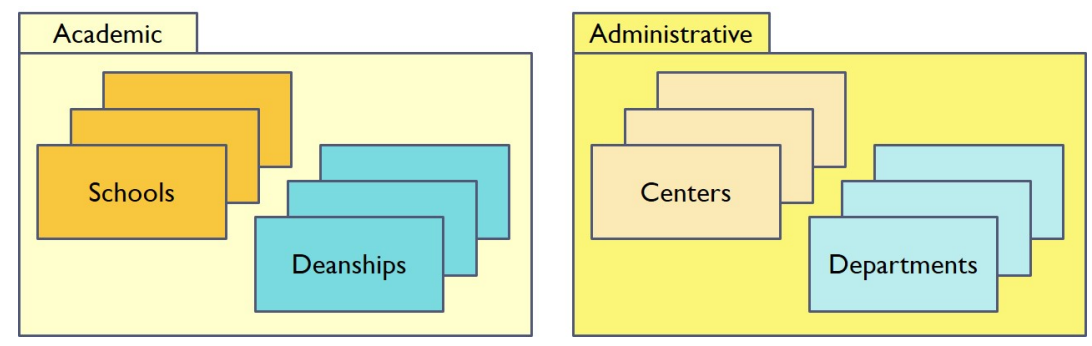

\subsection{Academic Content Types}

An academic content type is associated at the highest level with either a School or Deanship content type as shown in Figure 3. A deanship (e.g., Deanship of Student Affairs) differs from a school in that it does not offer any degrees and thus the need for two distinct academic types to accommodate the differences between the respective content structures. In addition, it is assumed that the content of the different schools pages is similar for website consistency and ease of use. In addition, the schools content should be centered on the core GJU strengths in order to entrench the GJU brand, mission, and message.

In that regard, each school page (see Figure 4) has been designed to include basic pages and information that most visitors would expect to find on a school website. An example on that are the 


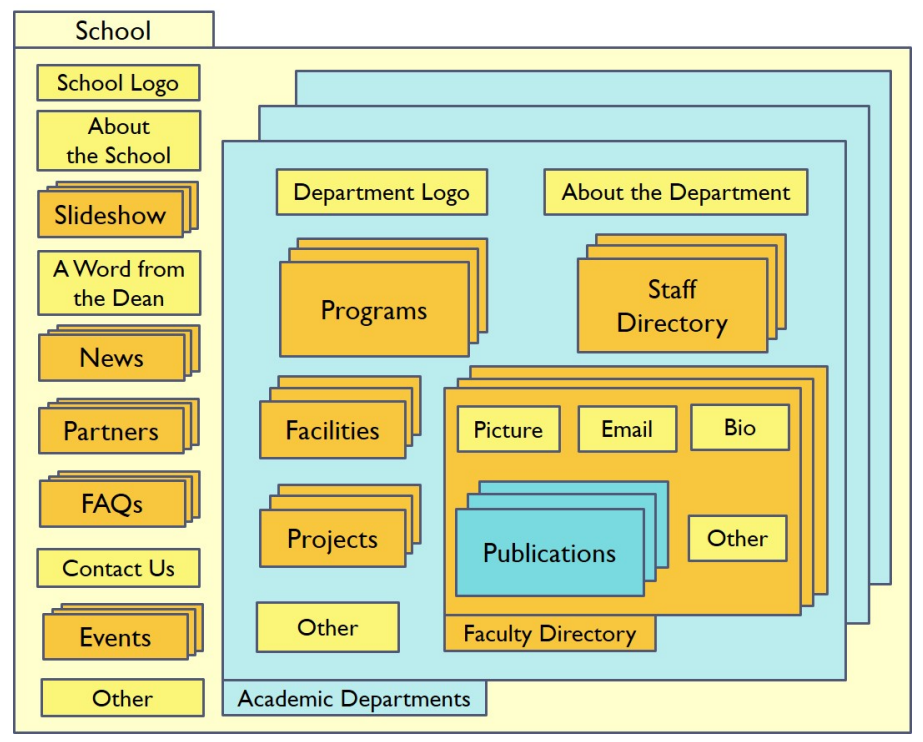

About the School, Word from the Dean, and Contact Us pages. The About the School page typically states the school's vision, mission, and values. The Word from the Dean page usually contains a message from the dean to welcome the prospective students and highlight the history, strength, and main offerings of the school. The Contact Us page provides phone numbers, emails, titles, and addresses of the contact persons responsible for providing information about the school. Also, each school is associated with a slideshow to present images of its activities, facilities, and school life and thus attract the eyes of the page visitors. A school can also be associated with lists (i.e., directories) of academic partners, industry partners, news, events, and frequently asked questions (FAQs) besides other information as required.

Furthermore, each school is associated with a list of departments. Each department is associated with basic data (e.g., title, logo, and email), an About the Department page, Contact Us page as well as lists of programs (undergraduate and graduate), faculty members, and staff members. Each program has a description and is associated with a list of study plans, which contain the courses that students needs to take in order to be eligible to graduate. A faculty member page contains basic contact data (e.g., picture, name, title, address, phone, email and webpages) as well as other optional information such as biography, education, research interests, experience, awards, and a list of publications. A staff member page contains the basic information of an administrative employee in the respective department. Additionally, a department can be associated with lists of facilities, laboratories, and research projects as well as any other needed information.

\subsection{Administrative Content Types}

Administrative entities (i.e., centers, departments and offices) complement the academic entities by offering a wide range of high quality services to all GJU stakeholders. The offerings of each entity are also centered on the core GJU strengths as applicable. Moreover, for consistency and usability reasons, the administrative entity pages have been designed to resemble the school pages as much as possible and as appropriate.

For example, and similarly to a school page, the brand, message, mission, and values of a center (or any administrative entity) are communicated via its logo, slideshow, About the Center page, and 
Word from the Director page as shown in Figure 5. Additionally, a center page contains a Contact Us page and lists of its staff, news, events, partners, and FAQs as applicable.

Suitably, other content types are also defined to cover the contrasting scopes of the different administrative entities. For instance, the Admission Department builds pages to present admission requirements, programs, fees, scholarships, and forms for use by prospective and enrolled students. Whereas, the Office for Industrial Links offers pages to show important information about the internship in Germany and list industry partners that support activities related to the German year, applied research and career development. On the other hand, the International Office provides pages to list the German partner universities as well as offer information regarding the German year and the trans-national staff exchange. In addition, the Information Systems and Technology Center offers pages to promote IT services that facilitate electronic learning and management.

\subsection{About GJU Content Type}

The About GJU page is designed to provide the website visitors with a quick overview of the university's brand, message, mission, values, identity, programs, research, people, and achievements. In that regard, the various pages (e.g., A Word from the President, German Dimension, and Testimonials) and lists (e.g., GJU programs, publications, faculty, and staff) that are associated with this content type are shown in Figure 5.

Figure 5. The Center, About GJU, and Media content types
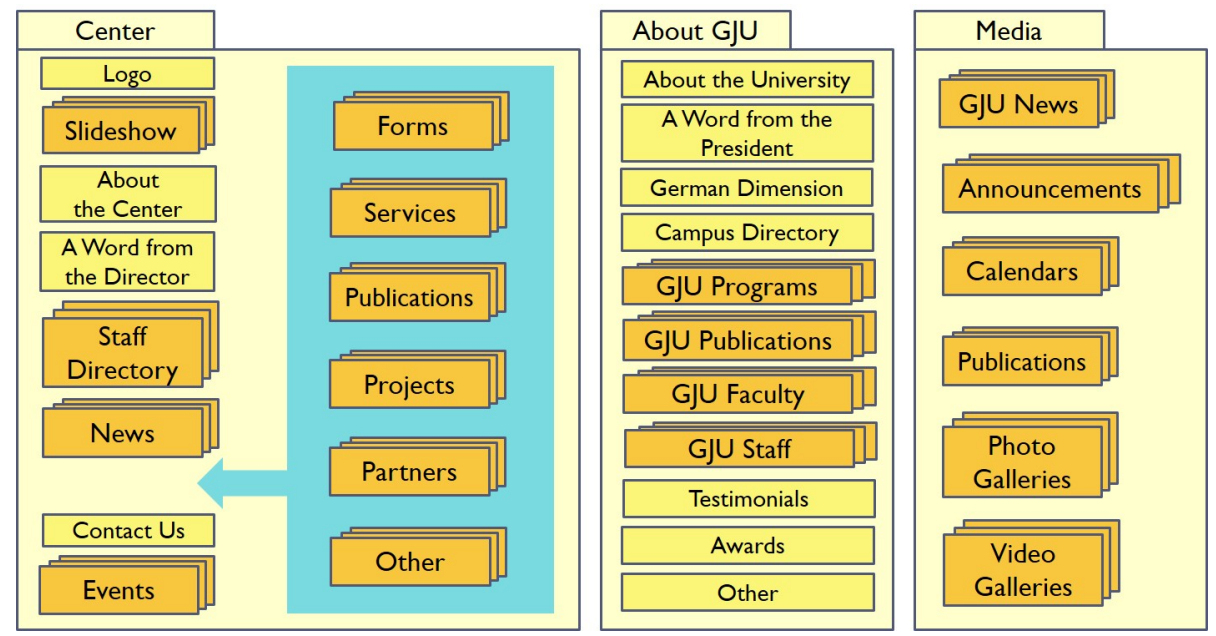

\subsection{Media Content Type}

The Media content type is introduced (see Figure 5) to allow the Public Relations Department to publish GJU news, announcements (e.g., admission period, registration period, exams period, classes start date, etc.), calendar events (e.g., seminar date and time, sport match day and time, holiday date, etc.), and general publications (e.g., periodicals, newsletters, magazines, year books, faculty publications, etc.). In addition, the media page contains photo and video galleries to engage visitors with eye-catching multimedia content covering GJU activities, campus life, testimonials, achievements, short films, etc. 


\section{DESIGN PHASE}

The website design phase comes after determining the required website content and its structure. It shapes not only the website layout and appearance, but also functionality, navigation, and usability. Therefore, this phase is given special attention as a poor design can drive visitors away from a website regardless of the quality of its content. The major design concerns are discussed in the next subsections.

\subsection{Templates}

Each website page is associated with a suitable design template based on its content. A template controls the layout of the page by dividing it into regions that are associated with suitable content types (e.g., School, Center, Photo Gallery, etc.), UI components (e.g., menu, form, calendar, slideshow, etc.), or HTML elements (e.g., image, link, button, body, list, etc.). The content of some regions (e.g., footer, main menu, and quick links) in a template is static in order to reuse it in all associated pages, whereas the content of other regions (e.g., news, events, side menu items, slideshow pictures, etc.) is dynamically determined based on the field values of the respective content type instances. Based on that, a well-designed template should emphasize content; make pages attractive; and make navigation intuitive.

The GJU website pages are mainly based on the front page and inner page templates that are shown in Figure 6. A few more custom templates are needed to support pages with different requirements such as the Photo Gallery and Contact Us pages as illustrated in Figure 7. Hence, all pages, except for the front page and custom pages, are associated with the inner page template. The GJU logo is included in all templates to maintain the brand identity on all pages. Similarly, all templates incorporate the main menu bar, quick links bar, as well as footer region to allow access to their respective content from any page and thus enhance the user experience. Furthermore, in all templates the main content regions are centered within a 1000px default width to fit in most computer screens.

Figure 6. The front and inner page templates
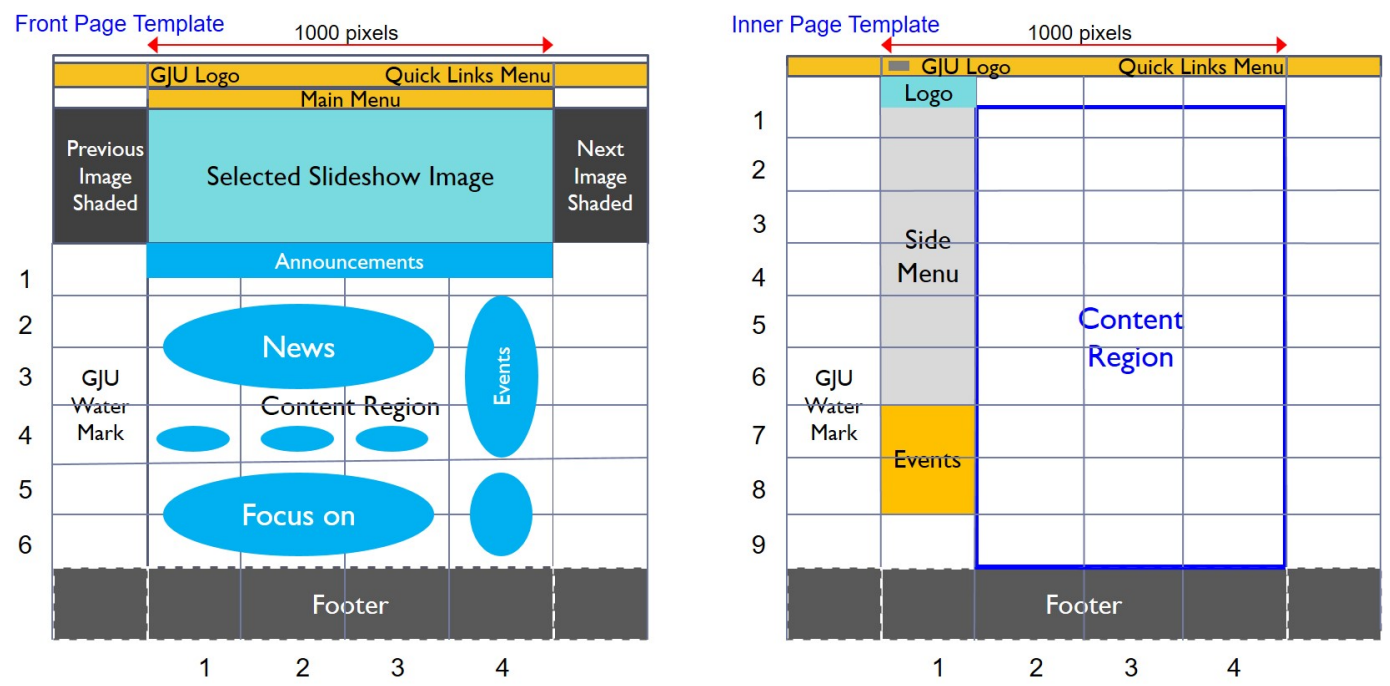

As shown in Figure 8, the main menu provides access to the pages of the academic and administrative entities; the pages that most visitors would normally try to find (i.e., the About GJU, Admission, Media, and Contact Us pages); as well as the pages that promote the German dimension 
Figure 7. The Photo Gallery and Contact Us custom page templates

Gallery Template

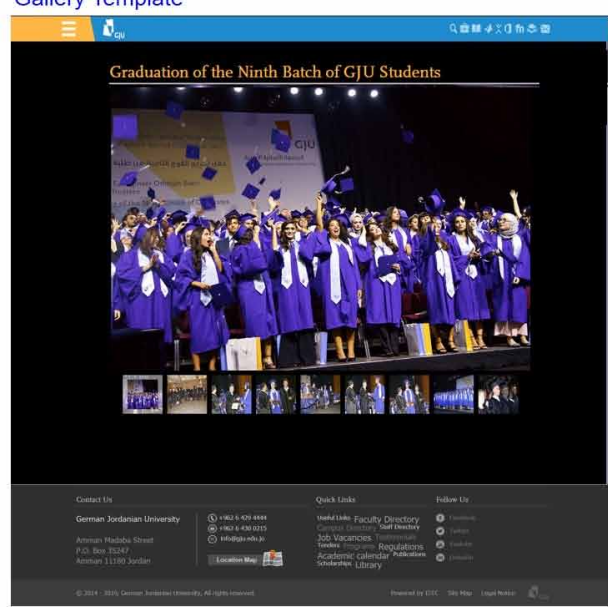

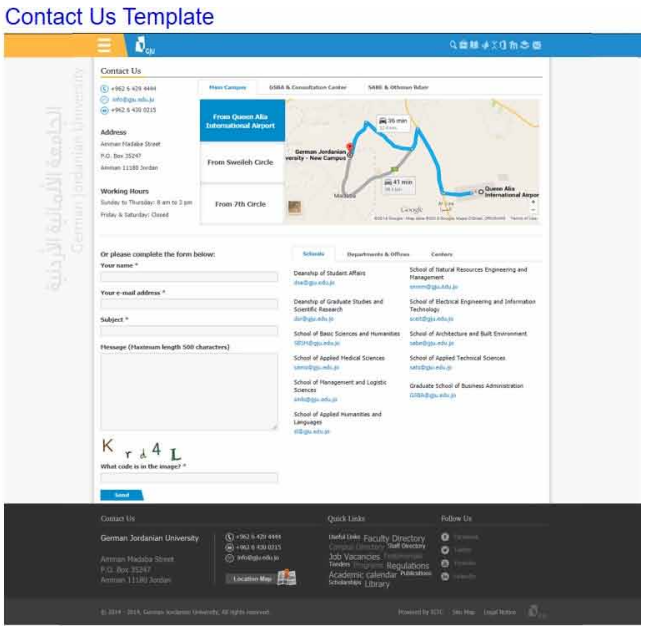

Figure 8. The GJU website front page

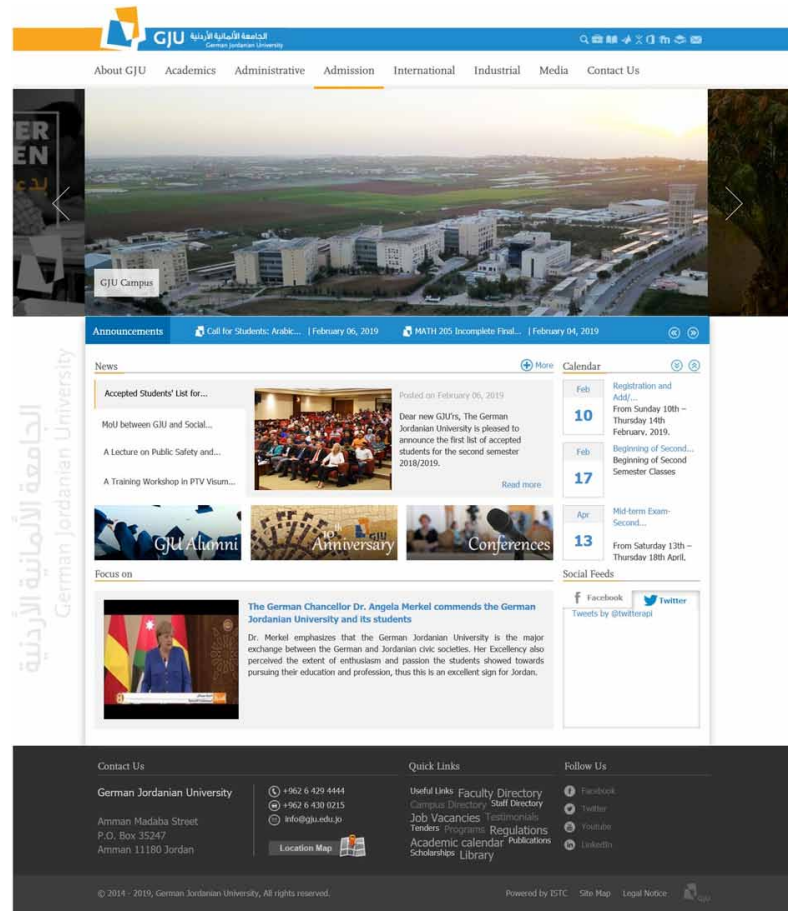

and university-industry linkage (i.e., the International page and Industrial page respectively). Besides, the quick links menu makes the search box and electronic services (e.g., Email, E-Learning, MyGJU portal (Al-Hawari et al., 2017), Office 365, library, and career services) handy from any page. Likewise, the footer provides access to basic contact information, location map, key content quick links, social media links, site map, copyright note, and legal notice. Further, clicking the GJU logo always navigates to the front page. 
In addition, the front page contains a slideshow as well as a content region that encapsulates multiple sub regions to display information such as news, announcements, and events. Importantly, all the previous content is frequently updated to continuously make the website interact with stakeholders and search engines in order to gain more visitors and achieve better rankings. Moreover, the arrangement and areas of those sub regions besides the spacing between them are all essential factors to make the content readable as well as maintain a consistent, attractive, and organized design. That can be accomplished by virtually splitting the content region both horizontally and vertically into cells as shown in Figure 6. Accordingly, the content region is placed in a grid of 6 (rows) by 4 (columns) cells within which each sub region is easily placed inside one or more cells in an organized manner. For example, the events sub region is placed inside cells $(2,4),(3,4)$ and $(4,4)$. In addition, the footer content is separated within four cells in order to nicely align each part with the content in its column.

Yet based on Figure 6, an inner page also contains the logo of its content in addition to a sidebar menu, events region (optional), and content region. The sidebar menu provides easy access to the content that is associated with the inner page. Accordingly, when a menu item is clicked its related content will be displayed in the content region. In addition, unlike the front page, the main menu is hidden by default in an inner page in order to increase the area of the content region and hence emphasize content. Still, the main menu can be opened, when needed, by clicking the open menu button that is located to the left of the GJU logo on the quick links bar. In that regard, the inner page for the School of Applied Technical Sciences (SATS) is shown in Figure 9. Suitably, the sidebar menu provides access to all content associated with SATS (e.g., About SATS, A Word from the Dean, Departments, Programs, Faculty Directory, Staff Directory, Research, Laboratories, Contact Us, etc.). In addition, the selected About SATS content is rendered in the content region and contains an engaging slideshow of important SATS activities.

Figure 9. A partial view from the SATS inner page

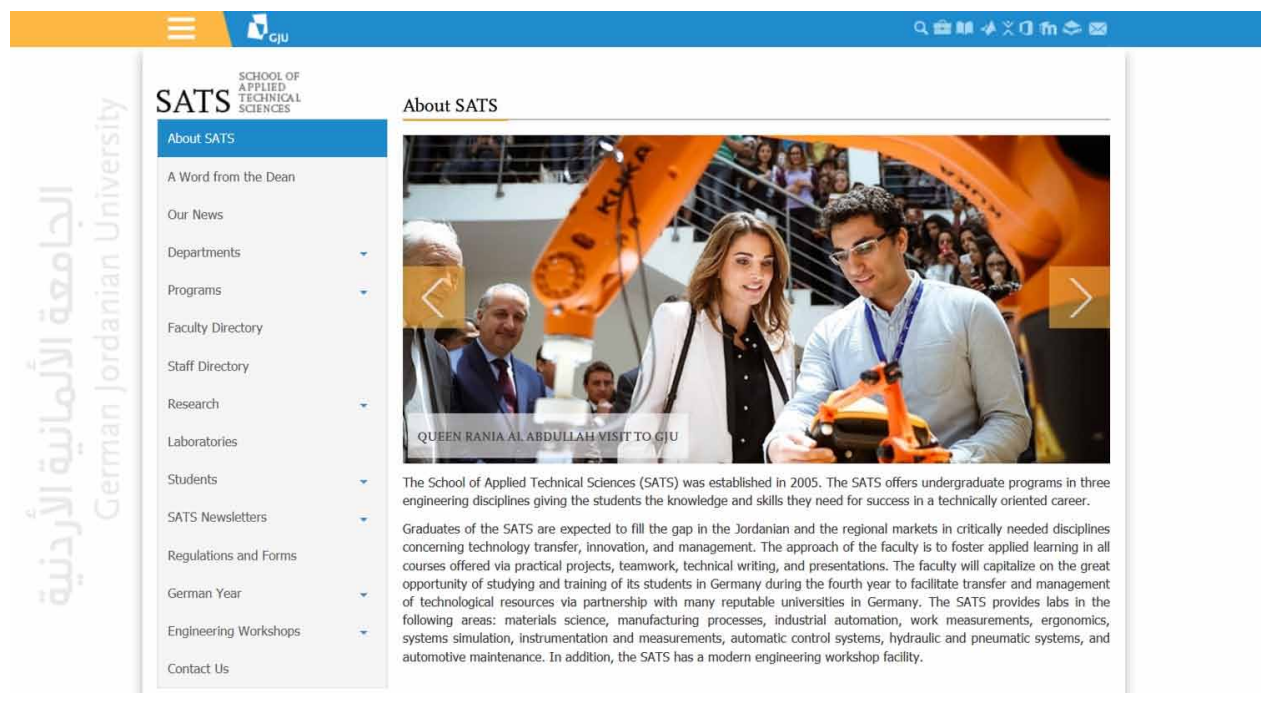

Not to mention, the style of regions, components, HTML elements, and text in a template is another important factor to consider as it affects the readability and attractiveness of the website pages. Accordingly, dark colored text on light background is used in content regions to achieve the best contrast and thus make the text stand out and readable. Whereas, a black background is applied 
Table 3. The number of clicks to access major content

\begin{tabular}{|l|l|l|}
\hline \multicolumn{1}{|c|}{ Content } & \# of Clicks & \multicolumn{1}{c|}{ Starting Point } \\
\hline $\begin{array}{l}\text { About GJU, Contact Us, Admission, Academic Entities, } \\
\text { Administrative Entities, International, Industrial, General } \\
\text { Publications, Periodicals, Photo Gallery, and Video Gallery }\end{array}$ & 1 & Main Menu \\
\hline $\begin{array}{l}\text { Undergraduate Programs, Faculty Directory, Staff Directory, } \\
\text { Campus Directory, Location Map, Library, Scholarships, } \\
\text { Regulations, Job Vacancies, Tenders, Useful Links, Social Media } \\
\text { Links, and Site Map }\end{array}$ & 1 & Footer \\
\hline $\begin{array}{l}\text { News, Announcements, Events, Calendar, Alumni, and } \\
\text { Conferences }\end{array}$ & 1 & Main Page \\
\hline Electronic and career services & 2 & Quick Links Bar \\
\hline $\begin{array}{l}\text { Graduate Programs and Faculty Publications } \\
\text { Admission Requirements, Tuition Fees, Grading System, } \\
\text { Admission FAQs }\end{array}$ & 2 & Footer \\
\hline $\begin{array}{l}\text { University Identity, German Dimension, and Awards } \\
\text { Faculty, School Staff, School Publications, School Projects, } \\
\text { School Research, School Facilities, School Contact Us, etc. }\end{array}$ & 2 & Menu \\
\hline $\begin{array}{l}\text { School Departments, School Programs, School News, School } \\
\text { Fiom on Main }\end{array}$ \\
\hline
\end{tabular}

in the Photo Gallery template (see Figure 7) to make the slideshow images catch the eye. In addition, the size, font and color of the title and body text are fixed in each template to maintain the website consistency as well as look and feel. Furthermore, the GJU logo brand colors (i.e., blue and orange) are utilized when applicable to convey the university identity.

\subsection{Usability}

The content structure and templates were designed with ease of use and intuitive navigation in mind. In that regard, the data in Table 3 demonstrates that most major website content can be easily reached in either 1 click or 2 clicks from the front page.

\subsection{Functionality}

Another design aspect to contemplate is functionality as accessing content using suitable UI components leads to an intuitive and engaging user experience. Some of the attractive UI components that are used in the GJU website are shown in Table 4. Accordingly, a list of nicely formatted regions for each news article lets visitors clearly and easily scan the news. An accordion component is suitable for presenting FAQs as it saves space and allows a user to focus on the answer of the desired question. A filtered list is a convenient tool to find and view faculty publications. A tabbed map enables users to intuitively and visually get directions to all GJU locations from three main places in Amman. Yet, a grid layout is utilized to arrange nicely designed photo albums for an enjoyable user experience.

\subsection{Responsiveness}

The website design and layout must be responsive to make the web pages render nicely on devices with different screen sizes. That is achievable by varying the design based on the used screen width as shown in the example in Figure 10. Accordingly, the design was dynamically modified to display all regions in one column in order to nicely fit them on the narrow screen that was used in this instance. That required replacing the main menu with a menu button on the quick links bar. In addition, the 
Table 4. Some of the attractive UI and design components that are used in the GJU website

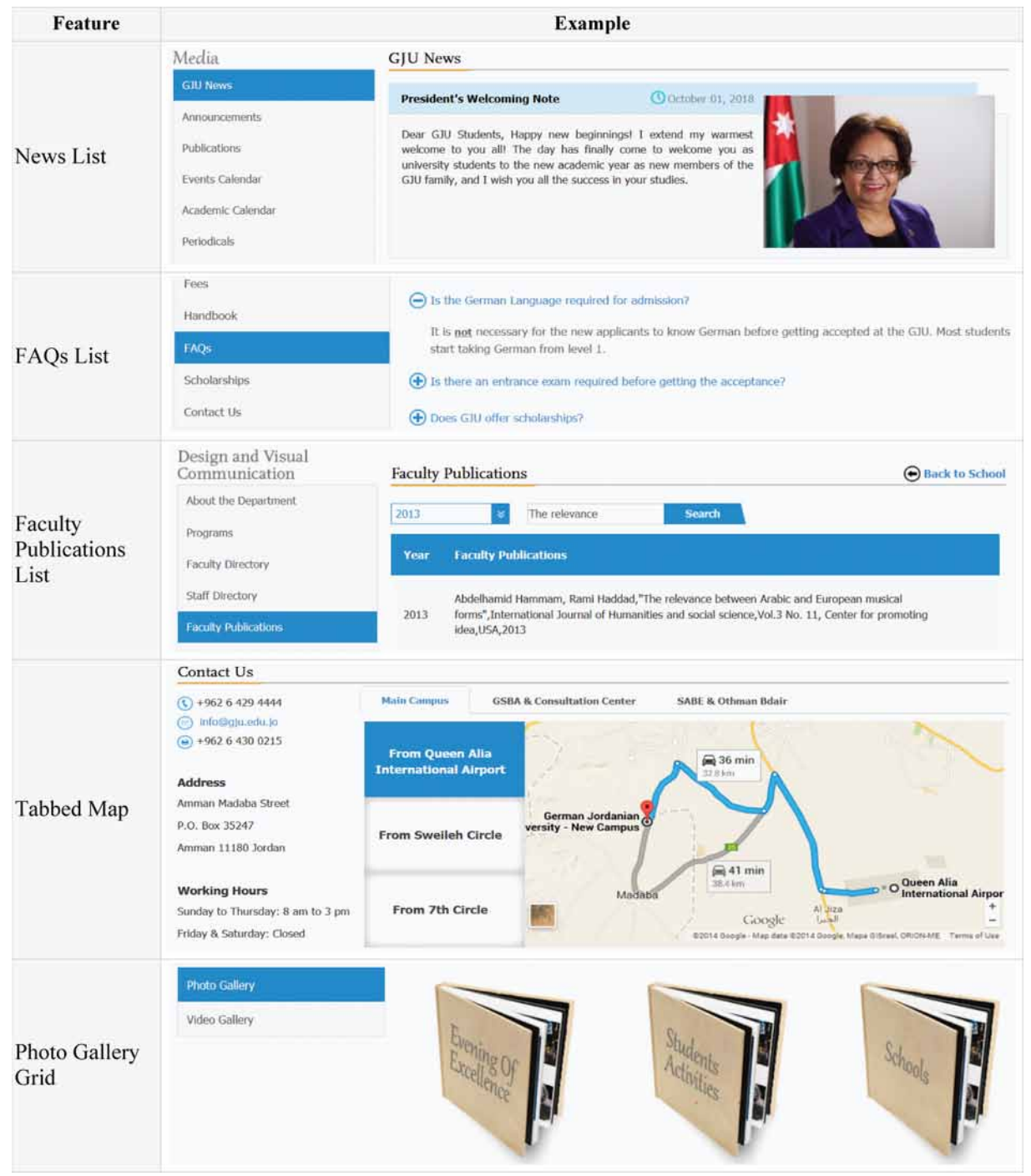

news tab was replaced with a news list, while hiding the news images and summaries. Moreover, the rest of the regions and the four footer cells were displayed one after another in one scrollable column.

\section{DEVELOPMENT PHASE}

This phase deals with the development framework, development steps, and content editing.

\subsection{Development Framework}

The free open-source Drupal CMS has been used to develop the GJU website (similarly to (Buell \& Sandford, 2018; Cheng \& Wang, 2012; Hubble, Murphy, \& Perry, 2011; Palwawankar, 2016; Ray \& Ramesh, 2017; Runceanu, Popescu, \& Borcoși, 2013; Satish, 2014)) because it is one of the most widely used CMS along with Joomla ("Joomla,") and WordPress ("WordPress,") according to (Black, 
Figure 10. The responsive front page displayed in a device with a small screen
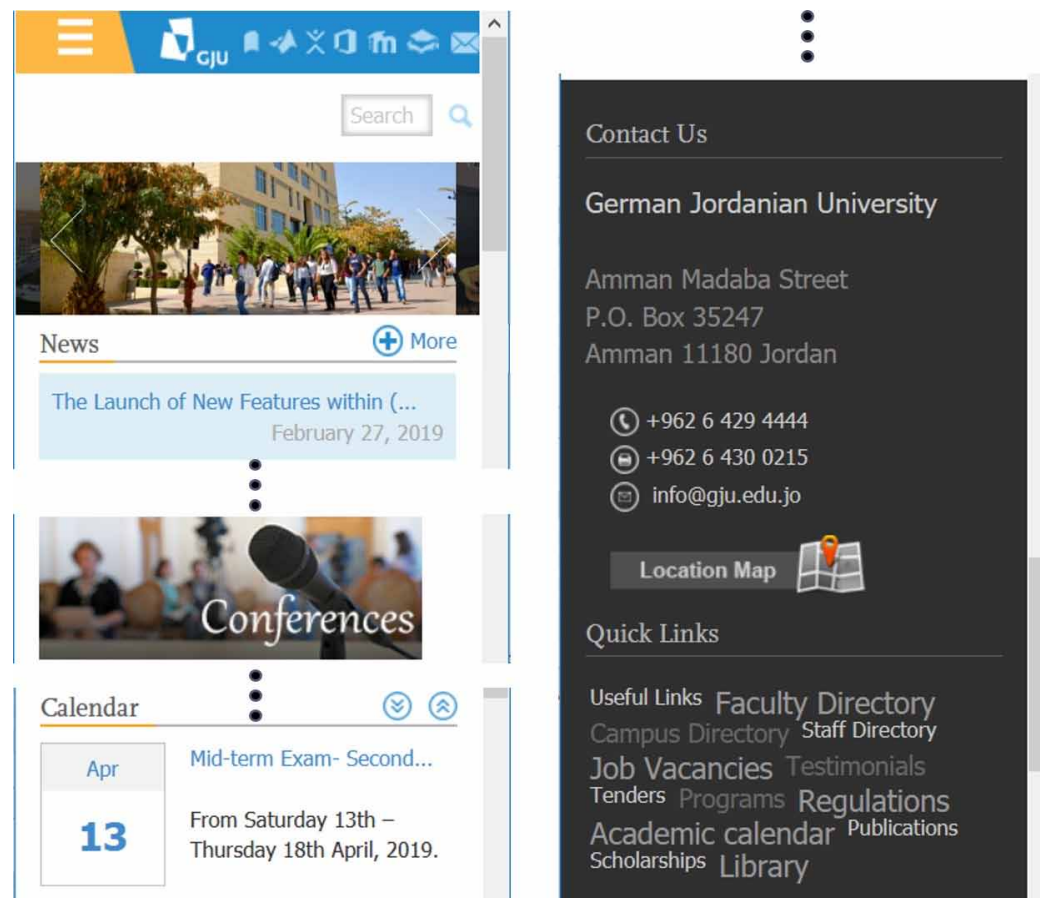

2011; Mirdha, Jain, \& Shah, 2014; Patel, Rathod, \& Prajapati, 2011). That is due to its flexibility, performance, security, and large developer community. Explicitly, Drupal is a PHP application that runs in a PHP engine on the website server machine as illustrated in Figure 11. Accordingly, Drupal's frontend controller (i.e., event loop) gets launched when running the index.php file. Consequently, upon receiving a page request from the Apache server, the controller dynamically renders the corresponding HTML page and then hands it back to Apache. In turn, Apache sends the page back to the user's browser for display. Not to mention, while rendering a requested page, the controller mostly interacts with the MySQL database management system to retrieve any needed content.

Figure 11. The Drupal architecture, files, data, and interactions

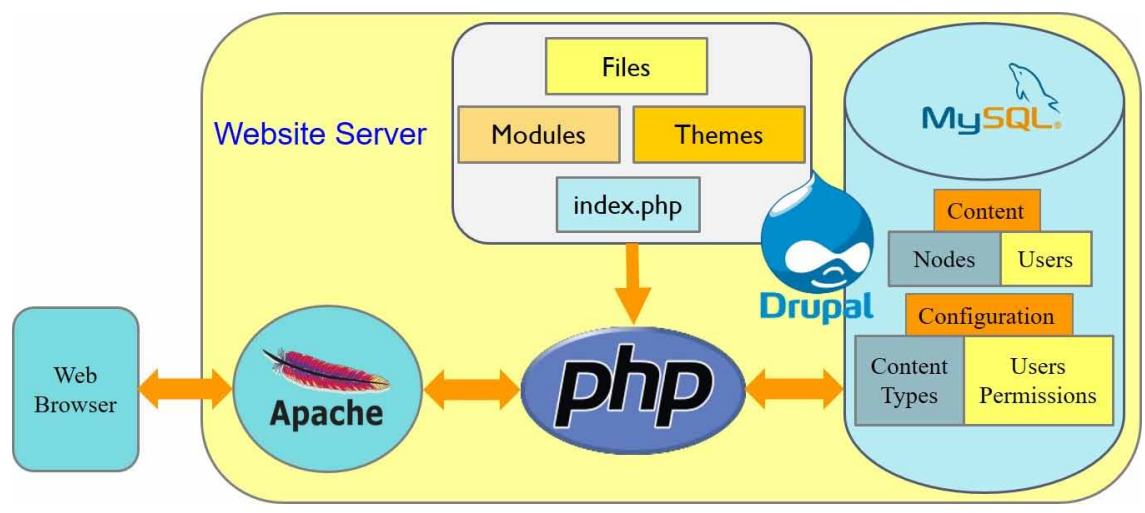


The Drupal installation is mainly comprised of modules, themes, and files. The modules are basically PHP scripts (i.e., code) that implement application logic to generate dynamic content. A theme (i.e., Drupal skin) includes the templates, CSS and .info (configuration file) files that are used by the theming engine to render the content in the appropriate regions (e.g., header, footer, content, sidebar, etc.) on the respective template (i.e., front, inner, or custom template). The installation also includes JavaScript (to control widgets), image (for logos or slideshows), and document (to be downloaded) files as needed to render the website pages.

The web-based Drupal administration portal supports simple user interfaces (e.g., menus, forms, etc.) for use by website administrators to manage configuration information (e.g., content types and users permissions) and content (nodes and users) data stored in the MySQL database. In that regard, Drupal allows defining structured and fielded content types (e.g., School, Department, Publication, $F A Q$, etc.) that are considered a blueprint for their respective content (i.e., nodes). Hence, a node is an actual piece of content that can be constructed by entering values in the fields of its content type, For example, the displayed data in the content region in Figure 9 is extracted from a SATS node of content type School. Moreover, a content type is associated with a block that is linked to a specific region in a template. Accordingly, the node field values are displayed in the region of the block that is associated with the node's content type. Besides, the formatting (i.e., layout, color, font, size, etc.) of the node's field values is determined based on the CSS class of the respective region.

Furthermore, Drupal's contributed Organic Groups (OG) module (“Organic Groups Module,”) has been installed in this project to allow defining a content type as a group and/or associating it with another group. For example, the Department content type is specified as a group and it is related to a School group. In addition, the Contact Us content type is not a group but it is associated with the Department group. The OG module also provides an option to associate a group with an OG menu. Thus, adding a child node to a group node with an enabled OG menu will result in placing a hyperlink to the child node on the menu of the group node. For instance, the Contact Us hyperlink on the sidebar menu in Figure 9 is in place because the Contact $U s$ node (i.e., a child node) was added to the SATS School node (i.e., a group node with an OG menu enabled).

Moreover, the view module ("Views Module,") allows displaying formatted lists as well as filtering content based on its group or node. For example, the News content type can be associated with several groups (e.g., School, Center, etc.). Based on that, when a News node is added it can be tagged with one or more group nodes. For instance and according to Figure 12, news article 5 is associated with nodes A, B and C; news article 2 is associated with nodes A and C; news article 6 is associated with nodes $\mathrm{B}$ and $\mathrm{C}$; news articles 1 and 4 are associated with node $\mathrm{A}$; news article 3 is associated with node $\mathrm{B}$; and news article 7 is associated with node $\mathrm{D}$. Accordingly, when the News content type has a view display and its menu link in node A is clicked, only the news articles of node A (i.e., 1, 2, 4, and 5) will be dynamically rendered by the corresponding view display.

Figure 12. Filtering content based on its group

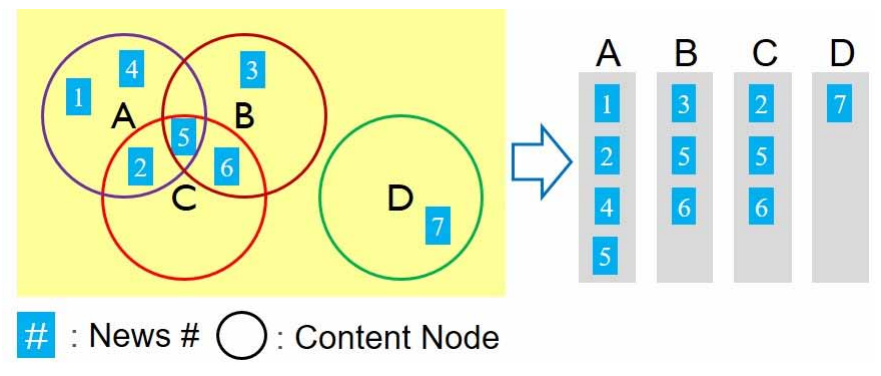


Drupal also supports permissions to control what users can perform and view via the administration portal. For example, the following permissions are available for each content type: add new content, edit own content, edit any content, delete own content, and delete any content. It also has permissions to administer menu items, image styles, HTML editor, and other features. More permissions to control executing PHP scripts, blocking users, and accessing backup files are also provided. In that regard, Drupal allows defining roles and assigning a specific set of permissions for each role as needed. For instance, the Administrator role is granted all permissions. Whereas, the School Editor and News Editor roles are each granted limited permissions to only allow managing (i.e., adding, editing, and deleting) School content and News articles respectively. Based on that, user accounts can also be defined and then assigned appropriate roles as needed in order to allow each corresponding website user to perform the designated administration and/or content editing duties.

\subsection{Development Steps}

The basic initial development and configuration steps to enable content editors to start adding School pages, for example, to the website are discussed next:

- $\quad$ The HTML elements and PHP code for the inner page template (shown in Figure 6) are added in the page.tpl.php file.

- The regions (e.g., Logo, Side Menu, and Content regions shown in Figure 6) used in the inner page template are defined in the Drupal bootstrap.info file.

- The Drupal Main Page Content block is linked to the Content region to display inner page content in that region by default.

- A content type named School is added via Drupal with field values as shown in Figure 13. Specifically, the Group field is set to true to consider each School as a group. In addition, the OG Menu field is set to true to designate each School content with a menu.

- A view named Group Content is defined.

- A Group Content display block for the School logo value (i.e., image) of a certain School node is defined and then linked to the Logo region to display the logo of a school in the Logo region.

- A Group Content display block for the OG Меnu of a School node is defined and then linked to the Side Menu region to display the menu of a certain school in the Side Menu region.

\section{Figure 13. The School content type}

\begin{tabular}{|c|c|c|}
\hline \multicolumn{3}{|c|}{$\begin{array}{l}\text { Home } \gg \text { Administration } » \text { Structure } » \text { Content types } » \text { School } \\
\text { School }\end{array}$} \\
\hline LABEL & MACHINE NAME & FIELD TYPE \\
\hline ¥ Title & title & Node module element \\
\hline \& OG Menu & og_menu & Enable OG Menu \\
\hline$\mp$ Group & group_group & Boolean \\
\hline * URL redirects & redirect & Redirect module form elements \\
\hline * URL path settings & path & Path module form elements \\
\hline + Body & body & Long text and summary \\
\hline \& School logo & field_school_logo & Image \\
\hline + Contact email & field_contact_email & Text \\
\hline
\end{tabular}


Next, the School content type needs to be associated with either a single page content type (e.g., the About the School content type) or a list view (e.g., to display a list of formatted FAQs or News items in the inner page content region) as specified in Figure 4. A content type named About the School is defined and is associated with the School content type to handle the first case. Whereas, associating a FAQs list with the School content type can be accomplished as follows:

- A content type named FAQ is defined with Question and Answer fields as shown in Figure 14. This content type is not a group, but it is associated with other groups (e.g., School, Department, etc.) through an Entity Reference field.

- A content type named FAQ Directory is needed to associate a School content type with a view that displays a list of $F A Q$ nodes. The association is accomplished by linking this type to its parent groups (e.g., School, Department, etc.) via an Entity Reference field.

- A Group Content display named FAQ of type Content Pane is defined as shown in Figure 15. Accordingly, the display formats the nodes (i.e., items) using the Views Accordion module; it displays nodes of content type FAQ; it uses the Question and Answer node fields to build each item; and it only filters (i.e., displays) the nodes that are linked to the Group ID of the parent (i.e., School in this example) node.

- A variant named FAQ Directory is added to the pages Node Template as shown in Figure 16. It links the FAQ Directory content type to the FAQ display of the Group Content view. Accordingly, when the FAQ Directory sidebar menu item of a specific school is clicked, the FAQ Directory variant uses the $F A Q$ display to build an accordion list of the $F A Q$ nodes that were added to that school for display in the content region (e.g., the FAQs list in Table 3).

\section{Figure 14. The FAQ content type}

\begin{tabular}{|c|c|c|c|c|}
\hline \multicolumn{3}{|l|}{ Home > Administration $>$ Structure $>$ Content types $>$ FAQ } & \multirow{3}{*}{\multicolumn{2}{|c|}{$\begin{array}{l}\text { ENTITY SELECTION } \\
\text { Mode * }\end{array}$}} \\
\hline $\mathrm{FAQ}$ & & & & \\
\hline LABEL & MACHINE NAME & FIELD TYPE & & \\
\hline & & & Organic groups & $v$ \\
\hline * Question & field_question & Long text & Target bundles & \\
\hline$\div$ Answer & field_answer & Long text and summary & $\begin{array}{l}\text { Department } \\
\text { Group } \\
\text { Ofices }\end{array}$ & \\
\hline * School / Department / About GJU & og_group_department_school_about & Entity Reference & $\begin{array}{l}\text { Other Sections } \\
\text { School } \\
\text { School Department }\end{array}$ & \\
\hline
\end{tabular}

\subsection{Content Editing}

The content editing tasks begin after the definition and configuration of the needed templates, content types, and administration UI. The web administrator is responsible for the initial management (e.g., addition, editing, and deletion) of the nodes (i.e., content) of the various content types via the dashboard shown in Figure 17. Accordingly, an administrator can add a new school or center by clicking the Add New School button or Add New Center button, respectively. Besides, for example, the administrator may click on the link of an added school (e.g., School of Applied Medical Sciences) or center (e.g., Information Systems and Technology Center) to edit its related content. Also, the text font, style, color, and size are preset in the CMS editor based on the style of the related content region to prevent changing the default style and therefore preserve the appearance and consistency of the website. Noting that the materials (e.g., programs, staff, partners, projects, news, events, publications, files, contact us, images, etc.) needed to enter the initial content must be provided by the respective entities. 
Figure 15. The FAQ display of the Group Content view

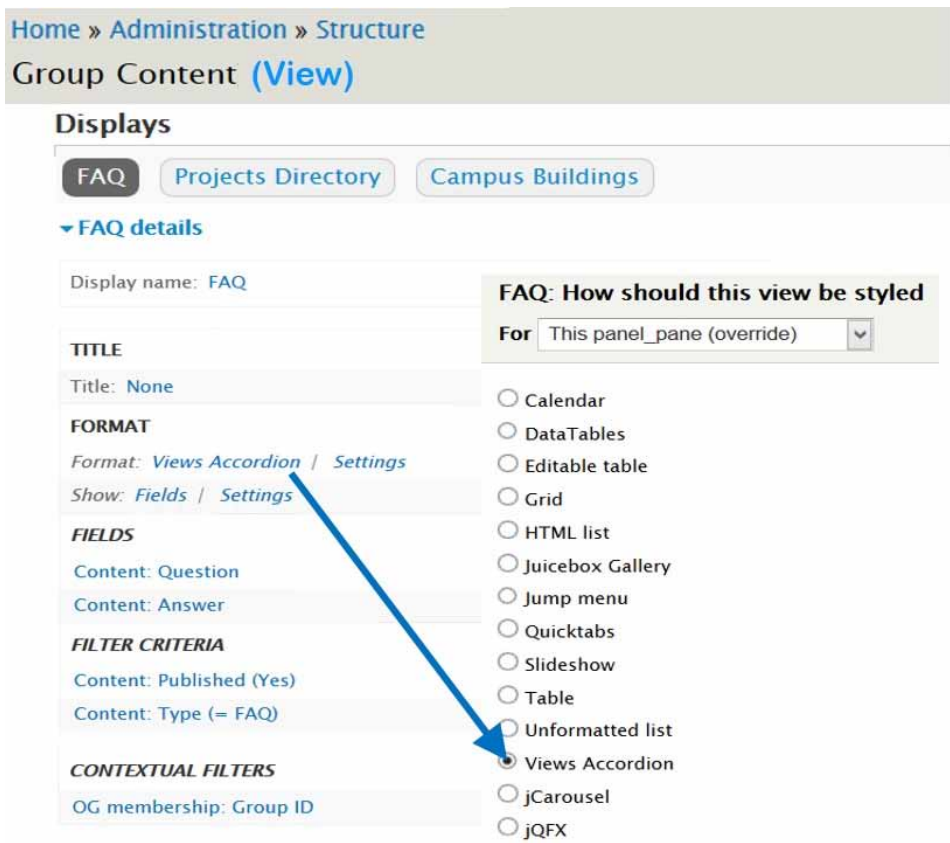

Figure 16. The FAQ Directory variant that links a FAQ Directory content type with its FAQ display

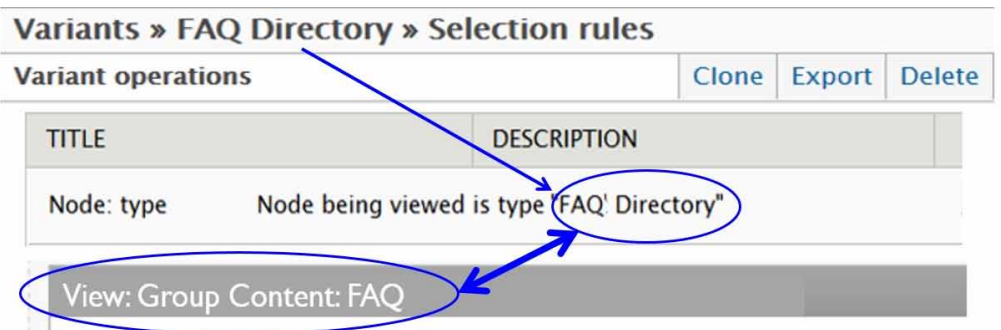

No title

Figure 17. A partial view of a content editor screen in the Drupal administration portal

\section{Schools \\ Graduate School of Business Administration \\ School of Applied Humanities and Languages \\ School of Applied Medical Sciences}

Add New School

\section{Centers}

Information Systems and Technology Center

Road Safety Center of Excellence

Vision Rehabilitation Center

Add New Center 


\section{LAUNCH PHASE}

The important steps to be considered in order to launch a website are discussed next.

\subsection{Testing Step}

Several test types must be performed to check the operation and quality of the developed website. Particularly, the unit, flow, and system tests must be conducted to evaluate several aspects concerning single pages, related pages, and all pages, respectively. Specifically, the tests validate the website for consistency (i.e., the brand, appearance, menu, and content compliance with the quality guidelines), usability (i.e., intuitive navigation and few clicks to reach content), spelling errors, grammatical mistakes, broken links, functionality (i.e., operation of slideshows, menus, tabs, maps, calendars, lists, etc.), cross-browser compatibility (i.e., action on different browsers such as Firefox, IE, chrome, etc.), and responsiveness (i.e., navigation and appearance on devices with different screen sizes). Furthermore, a non-functional load test has to be performed ahead of launching the website to make sure the website can scale up and function efficiently under normal and heavy (i.e., when many visitors are accessing the website) load conditions.

\subsection{Security Step}

The used CMS and the technology stack (i.e., Linux OS, MySQL RDBMS, and PHP engine) that it runs on are all free open-source software and thus extra care should be taken to secure them as follows:

- The Apache, Drupal, and MySQL default passwords, ports, usernames, and URLs should be all modified to other values.

- Strong passwords must be enforced for all administrators and content editors.

- Captcha and validation are added to the administration dashboard login screens, as well as any public website forms.

- The tools are customized to hide any environment related information in the error messages and error pages.

- The network security policy rules are set to block any access to the server machine, as well as the Apache, Drupal, and MySQL administration portals from outside the GJU intranet.

- The HTTPS protocol is enabled, and the HTTP protocol is disabled, in the Apache server for user authentication, data confidentiality, and data integrity purposes.

- The OS and all used software should be frequently updated and upgraded.

\subsection{User Accounts, Training and Documentation Steps}

The user roles (e.g., web administrator, content editor, news editor, etc.) has to be defined with permissions assigned to each role. The user accounts must also be added and assigned appropriate roles in order to allow users to perform their administrative and/or editing duties. The content editors have to be trained to use the CMS administration dashboard to start publishing their content. The documentation (e.g., user guide, development guide, security guide, and website guidelines) should be completed and released at this stage to serve as a guide for administrators, developers, and editors to do their tasks.

\subsection{Deployment and Analytics Steps}

The website can be officially launched by deploying it (i.e., Drupal, MySQL, and Apache) to the live server. It is also recommended upon deployment to perform some testing to make sure all is fine at this point. A promotional campaign (via workshops, social media, emails, news, etc.) is further needed at this stage to make the website apparent to all university stakeholders. Furthermore, the website must be linked to an analytics account (see subsection 9.1) for traffic analysis and reporting purposes. 


\section{MAINTENANCE PHASE}

Hosting a website in-house requires the following important measures to ensure its proper operation after its launch:

- Quality Assurance: This step involves testing the website as well as producing related analytics reports on a regular basis to detect and handle any issues related to the functionality, usability, compatibility, compliance, and performance of the website.

- Updates: This step deals with requests to define new content types, add new content nodes (e.g., adding a new school, center, or department), and edit exiting content (e.g., adding an article to a news list, adding an image to a slideshow, etc.).

- Administration: This step copes with administration operations such as system updates (e.g., patching Linux, upgrading Drupal, and updating Apache), data backups (e.g., server image, website files, and database dumps), and user accounts (i.e., all issues related to user accounts like activation, deactivation, roles, and passwords).

- Training: Training sessions must also continue on a regular basis to train the content editors (i.e., new and previous editors) on how to manage their designated pages via Drupal and how to abide by the website quality standards.

\section{VALIDATION METHODS}

The website quality attributes have been evaluated quantitatively and qualitatively using google analytics ("Google Analytics,") and user survey based methods as discussed next.

\subsection{Google Analytics}

The website has been added to the GJU Google analytics account for traffic analysis and reporting purposes. Based on that, the daily distribution of the website visitors from March $1^{\text {st }} 2018$ till March $1^{\text {st }} 2019$ is shown in Figure 18 (noting that all the reported data in this subsection are collected in that same period). Accordingly, a total of 539616 people visited the website throughout the year with an average of about 1474 visitors per day, a minimum of 593 visitors on June $15^{\text {th }} 2018$, and a maximum of 3966 visitors on September $25^{\text {th }} 2018$. Those numbers assert that the website is up to date, content-rich, and highly available since the stakeholders constantly seek the website on a daily basis for information without any interruption of service.

Figure 18. The daily distribution of the website users from March 1, 2018 to March 1, 2019

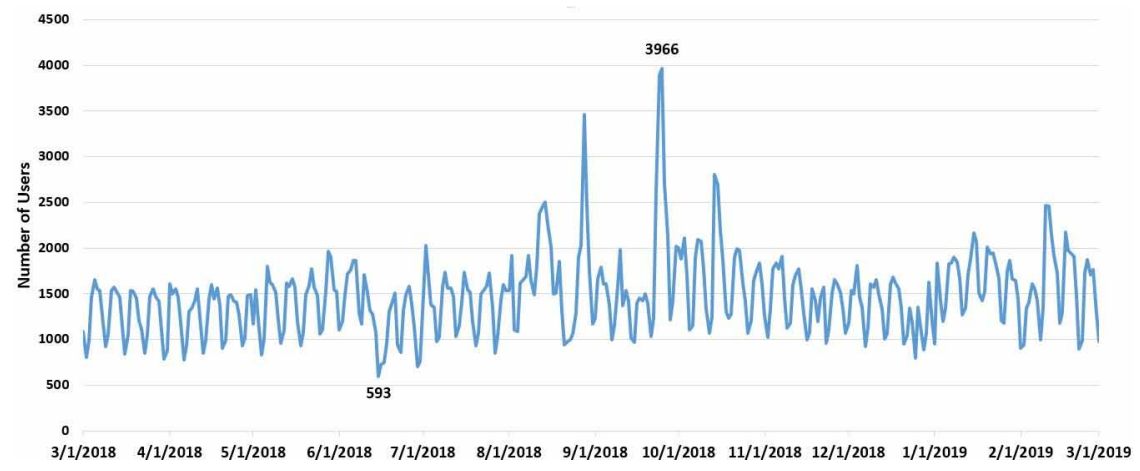


According to Figure 19, the average website bounce rate (i.e., the percentage of users who navigate away from the website after viewing only one page), number of viewed website pages per session, and user session duration are $26.73 \%, 2.64$ pages, and 2:47 seconds respectively, which confirm that the website is engaging. In addition, the fact that the top website visitors (out of visitors from 189 countries) are from Jordan (first), Germany (second), United States (third), Middle East, United Kingdom, India, Canada, and China reflects the German dimension and international aspects of the website.

Figure 19. The top website users by country and average user behavioral statistics from March 1, 2018 to March 1, 2019

\begin{tabular}{|c|c|c|c|c|c|c|}
\hline \multirow[b]{2}{*}{ Country ? } & \multicolumn{3}{|l|}{ Acquisition } & \multicolumn{3}{|l|}{ Behavior } \\
\hline & Users ? $\quad \downarrow$ & New Users ? & Sessions ? & Bounce Rate ? & $\begin{array}{l}\text { Pages / } \\
\text { Session ? }\end{array}$ & $\begin{array}{l}\text { Avg. Session } \\
\text { Duration ? }\end{array}$ \\
\hline & $\begin{array}{r}210,504 \\
\text { \% of Total: } 100.00 \% \\
(210,504)\end{array}$ & $\begin{array}{r}200,552 \\
\text { \% of Total: } 100.17 \% \\
(200,205)\end{array}$ & $\begin{array}{r}718,917 \\
\text { \% of Total: } 100.00 \% \\
(718,917)\end{array}$ & $\begin{array}{r}26.73 \% \\
\text { Avg for view: } \\
26.73 \%(0.00 \%)\end{array}$ & $\begin{array}{r}2.64 \\
\text { Avg for View: } \\
2.64(0.00 \%)\end{array}$ & $\begin{array}{r}00: 02: 47 \\
\text { Avg for View: } \\
00: 02: 47(0,00 \%)\end{array}$ \\
\hline 1. $\Xi$ Jordan & 140,281 (65.33\%) & $131,345(65.4996)$ & $591,479(82,27 \%)$ & $23.99 \%$ & 2.52 & 00:02:45 \\
\hline 2. 国 Germany & $16,375 \quad(7.63 \%)$ & $14,573 \quad(7.2796)$ & $41,874 \quad(5.82 \%)$ & $29.29 \%$ & 3.11 & 00:03:08 \\
\hline 3. 国 United States & $7,621 \quad(3.55 \%)$ & $7,261 \quad(3.62 \%)$ & $10,170 \quad(1.41 \%)$ & $56.98 \%$ & 2.48 & 00:01:40 \\
\hline 4. 回 Saudi Arabia & $6,734 \quad(3.14 \%)$ & $6,253 \quad(3.12 \%)$ & $11,123 \quad(1.55 \%)$ & $33.40 \%$ & 4.06 & 00:03:30 \\
\hline 5. 드 United Arab Emirates & $\mathbf{5 , 1 8 7}(2.42 \%)$ & $4,778 \quad(2.38 \%)$ & $9,342 \quad(1,30 \%)$ & $29.84 \%$ & 4.29 & 00:03:44 \\
\hline 6. $\doteq$ India & $3,855 \quad(1.80 \%)$ & $3,817 \quad(1.90 \%)$ & $4,675 \quad(0.65 \%)$ & $57.01 \%$ & 2.58 & 00:02:06 \\
\hline 7. 閶 United Kingdom & $2,283 \quad(1.06 \%)$ & $2,022 \quad(1.01 \%)$ & $3,246(0.45 \%)$ & $43.68 \%$ & 3.09 & 00:02:17 \\
\hline 8. 口 Palestine & $1,849 \quad(0.86 \%)$ & $1,769 \quad(0.88 \%)$ & $3,012 \quad(0,42 \%)$ & $36.09 \%$ & 3.94 & 00:03:35 \\
\hline 9. $\equiv$ Egypt & $1,839 \quad(0.86 \%)$ & $1,760 \quad(0.8896)$ & $2,523 \quad(0,35 \%)$ & $46.18 \%$ & 2.97 & $00: 02: 56$ \\
\hline 10. $匚$ Kuwait & $1,693 \quad(0.79 \%)$ & $1,545 \quad(0.7796)$ & $3,321 \quad(0,46 \%)$ & $28.79 \%$ & 3.94 & 00:03:39 \\
\hline 11. Qatar & $1,665 \quad(0.78 \%)$ & $1,525 \quad(0.76 \%)$ & $2,948 \quad(0.41 \%)$ & $31.58 \%$ & 4.14 & 00:03:32 \\
\hline 12. Turkey & $1,498 \quad(0.70 \%)$ & $1,288 \quad(0,64 \%)$ & $2,344 \quad(0.33 \%)$ & $39.80 \%$ & 2.71 & 00:02:00 \\
\hline 13. China & $1,181 \quad(0.55 \%)$ & $1,173 \quad(0.58 \%)$ & $1,230 \quad(0.17 \%)$ & $87.64 \%$ & 1.41 & 00:00:42 \\
\hline 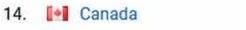 & $1,065 \quad(0.50 \%)$ & $1,025 \quad(0.51 \%)$ & $1,455 \quad(0.20 \%)$ & $46.12 \%$ & 3.46 & 00:02:14 \\
\hline 15. $=$ Iraq & 923 (0.43\%) & $902(0.45 \%)$ & $1,256(0.17 \%)$ & $48.81 \%$ & 2.97 & $00: 02: 53$ \\
\hline
\end{tabular}

The top 22 visited website pages are reported in Figure 20. Based on that, the most sought website information is related to the following content: job vacancies, e-learning, admission, fees, academic calendar, programs, news, announcements, about GJU, schools, international office, tenders, and contact us page. Hence, the website is obviously engaging different stakeholders in information related to the core GJU strengths such as education, German dimension, and services.

Based on Figure 21, it is obvious that the majority of the users access the website from devices with varying screen sizes that run either Windows (i.e., computers), iOS (i.e., phones and tablets), or Android (i.e., phones and tablets), which establishes the fact that the website is responsive. Moreover, the related performance measurements are illustrated in Figure 22. Accordingly, all values are acceptably fast (i.e., in fractions of a second) except for the 4.36 average page load time that needs more improvement.

\subsection{User Survey}

A user survey was conducted for about two weeks to evaluate the quality attributes of the GJU website. The answer to each question is assessed according to the five points Likert scale (Likert, 
Figure 20. The top 22 visited website pages from March 1, 2018 to March 1, 2019

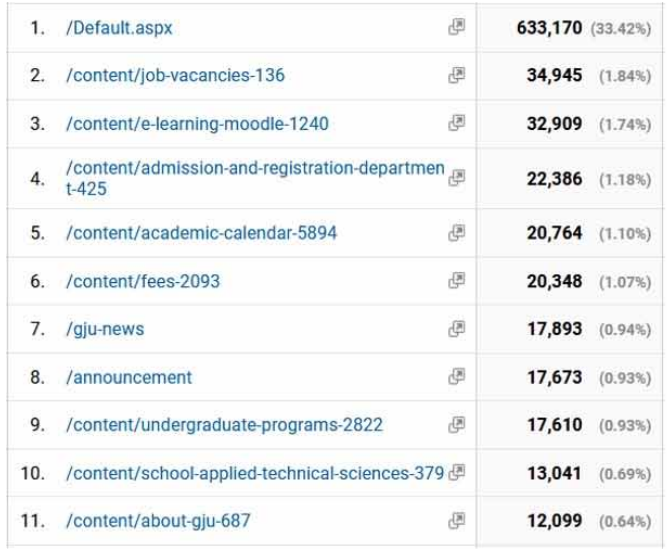
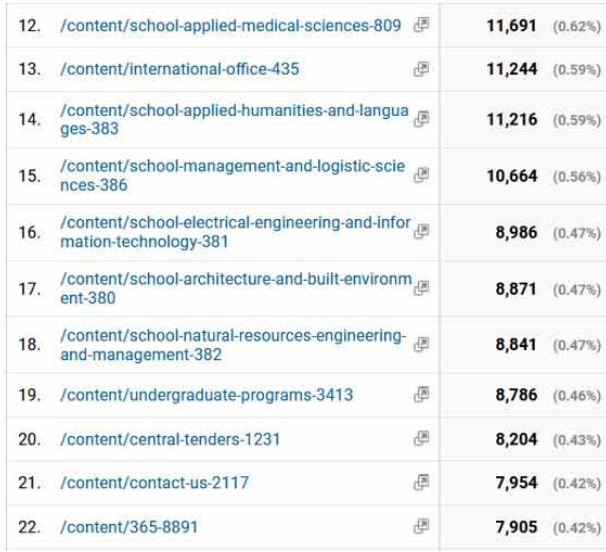

Figure 21. The top 5 operating systems used by users to access the website from March 1, 2018 to March 1, 2019

\begin{tabular}{lrc}
\multicolumn{1}{l}{ Operating System } & Users & \% Users \\
\hline 1. Windows & 85,648 & $40.79 \%$ \\
\hline 2. iOS & 60,852 & $28.98 \%$ \\
\hline 3. Android & 52,145 & $24.84 \%$ \\
\hline 4. Macintosh & 8,247 & | $3.93 \%$ \\
\hline 5. Linux & 2,122 & $1.01 \%$ \\
\hline
\end{tabular}

Figure 22. The website performance related measurements from March 1, 2018 to March 1, 2019

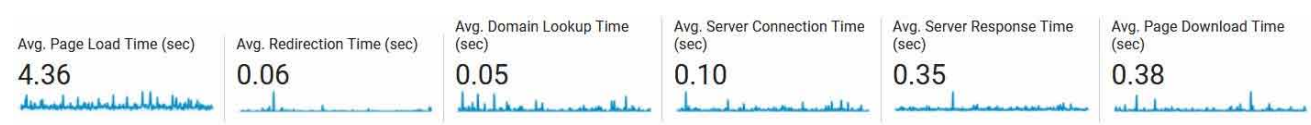

1932) as follows: Strongly Agree (5 points), Agree (4 points), Neutral (3 points), Disagree (2 points), and Strongly Disagree (1 point). Accordingly, the quality attribute that each question is measuring, the number of responses to each question answer, the total answers to each question, and the average score for each question are all reported in Table 5.

Based on that, question 1 is the most answered question (with 1050 participants) and question 9 is the least answered question (with 1007 participants). The average score of every question was around 4 and that is very promising. Specifically, most participants strongly agreed or agreed that the website: is engaging (923 out of 1050 responses i.e., $88 \%$ of the responses), is easy to use (821 out of 1027 related responses i.e., $80 \%$ of the responses), is easy to navigate ( 830 out of 1019 related responses i.e., $81 \%$ of the responses), is structured ( 822 out of 1013 responses i.e., $81 \%$ of the responses), is content rich (746 out of 1010 related responses i.e., $74 \%$ of the responses), is attractive (789 out of 1009 related responses i.e., $78 \%$ of the responses), is fast (740 out of 1016 responses i.e., $73 \%$ of the responses), is available (813 out of 1005 related responses i.e., $81 \%$ of the responses), and is reliable (710 out of 1007 related responses i.e., $71 \%$ of the responses). Based on that, the quality attributes that need more improvement than others are: content, speed, and reliability. 
Table 5. The GJU user survey results

\begin{tabular}{|c|c|c|c|c|c|c|c|c|c|}
\hline \multirow{2}{*}{$\#$} & \multirow{2}{*}{ Question } & \multirow{2}{*}{$\begin{array}{c}\text { Quality } \\
\text { Attribute }\end{array}$} & \multicolumn{5}{|c|}{ Answers } & \multirow{2}{*}{$\begin{array}{c}\text { Total } \\
\text { Answers }\end{array}$} & \multirow{2}{*}{$\begin{array}{c}\text { Average } \\
\text { Score }\end{array}$} \\
\hline & & & 5 & 4 & 3 & 2 & 1 & & \\
\hline 1 & $\begin{array}{l}\text { I visit the } \\
\text { website } \\
\text { frequently }\end{array}$ & Engaging & 504 & 419 & 67 & 27 & 33 & 105 & 4.270 \\
\hline 2 & $\begin{array}{l}\text { I cn access } \\
\text { the desired } \\
\text { information } \\
\text { in a few } \\
\text { clicks }\end{array}$ & Easy to use & 368 & 453 & 141 & 29 & 36 & 1027 & 4.059 \\
\hline 3 & $\begin{array}{l}\text { The website } \\
\text { is easy to } \\
\text { navigate }\end{array}$ & Navigation & 391 & 439 & 118 & 40 & 31 & 1019 & 4.098 \\
\hline 4 & $\begin{array}{l}\text { The website } \\
\text { is organized }\end{array}$ & Structured & 348 & 474 & 122 & 40 & 29 & 101 & 4.058 \\
\hline 5 & $\begin{array}{l}\text { I fund the } \\
\text { needed } \\
\text { content on } \\
\text { the website }\end{array}$ & Content rich & 300 & 446 & 171 & 56 & 37 & 101 & 3.907 \\
\hline 6 & $\begin{array}{l}\text { Thewebsite } \\
\text { design is } \\
\text { nice and } \\
\text { simple }\end{array}$ & Attractive & 345 & 444 & 129 & 58 & 33 & 100 & 4.001 \\
\hline 7 & $\begin{array}{l}\text { Thewebsite } \\
\text { navigation } \\
\text { is fast }\end{array}$ & Fast & 311 & 429 & 176 & 64 & 36 & 101 & 3.901 \\
\hline 8 & $\begin{array}{l}\text { I cn access } \\
\text { the website } \\
\text { anytime }\end{array}$ & Available & 408 & 405 & 115 & 45 & 32 & 100 & 4.106 \\
\hline 9 & $\begin{array}{l}\text { I rrely find } \\
\text { broken } \\
\text { links on the } \\
\text { website }\end{array}$ & Reliable & 343 & 367 & 208 & 46 & 43 & 100 & 3.915 \\
\hline
\end{tabular}

\section{SUMMARY AND CONCLUSION}

A suitable website development process that is comprised of six phases (i.e., requirements, content, design, development, launch, and maintenance) has been proposed for the development of university websites that are content-based, relatively simple, and non-interactive. Besides, it has been suggested that a CMS is more suitable than a PHP, JSF, or ASP framework for website development because it does not require advanced programming skills or model-driven languages.

A university website is identified as a main online-presence and marketing channel. Therefore, it should make a strong first impression to attract more visitors, as well as reflect the university brand, values, mission, strengths, and programs. Appropriately, proper content types and structure were proposed in the content phase to reveal the university strengths and values, as well as make the site easy to use and intuitive to navigate. Furthermore, the design concerns that make the website engaging were identified. Consequently, proper design guidelines were introduced to enhance the appearance, navigation, usability, responsiveness, and functionality of university websites. 
The Drupal CMS features and advantages were also highlighted. Accordingly, the steps to build dynamic web pages using a UI-based CMS, rather than programming-based frameworks, have been identified and illustrated. In that regard, the OG module was specifically installed to define any content type (e.g., Department) as a group and to associate it, if applicable, with another parent group (e.g., School). That way, the whole content structure can be constructed and the content can be defined once and then reused in any related pages. Moreover, the view module was utilized to display nicely formatted lists (e.g., a list of FAQs) and to filter content dynamically based on its group or node.

The accounts, roles, and permissions features of Drupal were discussed to show how multiple collaborators (e.g., administrators and content editors) can manage the content of their related departments using a simple dashboard. Further, several test types (e.g., unit test, flow test, system test, and load test) were suggested to verify the different capabilities of the website.

The measures to secure open-source CMS and technology-stack in the launch phase were also proposed. Based on that, the default ports, passwords, and usernames of all used portals must be modified. Besides, validation, environment hiding, and strong password mechanisms need to be adopted. Further, the HTTPS should be enabled in the Apache server to guarantee the data confidentiality and integrity. Also, proper network policy rules must be defined to block user-access to all administrative portals from outside the GJU intranet.

The significance of the maintenance phase was also emphasized as it deals with important measures such as quality assurance, updating content, training the content editors on using the CMS, and administration tasks (e.g., systems updates, data backups, and user accounts management).

Finally, google analytics and user survey methods were utilized to evaluate the quality attributes of the GJU website. Accordingly, the results illustrated that the GJU website is content rich, attractive, engaging, organized, easy to use, responsive, fast, and available. 


\section{REFERENCES}

Al-Hawari, F. (2017). Analysis and design of an accounting information system. International Research Journal of Electronics and Computer Engineering, 3(2), 16-21. doi:10.24178/irjece.2017.3.2.16

Al-Hawari, F., \& Barham, H. (2019). A machine learning based help desk system for IT service management. Journal of King Saud University-Computer and Information Sciences. 10.1016/j.jksuci.2019.04.001

Al-Hawari, F., Alufeishat, A., Alshawabkeh, M., Barham, H., \& Habahbeh, M. (2017). The software engineering of a three-tier web-based student information system (MyGJU). Computer Applications in Engineering Education, 25(2), 242-263. doi:10.1002/cae.21794

Amrahov, S. (2016). Implementation of search engine optimization techniques for dynamic website (Ph.D.). Khazar University.

Bernier, J., Barchéin, M., Cañas, A., Gómez-Valenzuela, C., \& Merelo, J. (2002). The services a university website should offer. Information Society Education: Monitoring a Revolution, 9, 1746-1750.

Bin, W., Bingyun, G., Peishun, L., \& Xiaoqing, L. (2018). A study on tactics for college website at search engine optimization. Paper presented at the 3rd International Conference on Big Data Analysis (ICBDA). doi:10.1109/ ICBDA.2018.8367688

Black, E. L. (2011). Selecting a web content management system for an academic library website. Information Technology and Libraries, 30(4), 185-189. doi:10.6017/ital.v30i4.1869

Buell, J., \& Sandford, M. (2018). From Dreamweaver to Drupal: A university library website case study. Information Technology and Libraries, 37(2), 118-126. doi:10.6017/ital.v37i2.10113

Cheng, X., \& Wang, Z. (2012). The web development based on the drupal system. Paper presented at the Second International Conference on Business Computing and Global Informatization. Drupal - Open Source CMS. Retrieved from https://www.drupal.org/

Ford, W. G. (2011). Evaluating the effectiveness of college web sites for prospective students. Journal of College Admission, 212, 26-31.

Friedlein, A. (2001). Web project management: delivering successful commercial web sites. Morgan Kaufmann.

Gehrke, D., \& Turban, E. (1999). Determinants of successful website design: relative importance and recommendations for effectiveness. Proceedings of the 32nd Annual Hawaii International Conference on Systems Sciences. Retrieved from https://www.gju.edu.jo

Google Analytics. (2020). Retrieved from https://analytics.google.com

Group, N. D. (2020). Web design process - behind the scenes [INFOGRAPHIC]. Retrieved from https://www. newdesigngroup.ca/website-design/web-design-process-infographic/

Hubble, A., Murphy, D. A., \& Perry, S. C. (2011). From static and stale to dynamic and collaborative: The Drupal difference. Information Technology and Libraries, 30(4), 190-197. doi:10.6017/ital.v30i4.1870

IFML. (2020). The Interaction Flow Modeling. Retrieved from https://www.ifml.org/

Joomla. (2020). Retrieved from https://www.joomla.org/

Kelo, A. (2017). Internal website development process. (Masters). Helsinki Metropolia University of Applied Sciences.

Kumari, P., \& Nandal, R. (2017). A research paper on website development optimization using xampp/php. International Journal of Advanced Research in Computer Science, 8(5), 1231-1235.

Laporte, C. Y., O'Connor, R. V., \& Paucar, L. H. G. (2015). The implementation of ISO/IEC 29110 software engineering standards and guides in very small entities. Paper presented at the International Conference on Evaluation of Novel Approaches to Software Engineering. doi:10.5220/0005368500050015

Likert, R. (1932). A technique for the measurement of attitudes. Archives de Psychologie, 22(140), 1-55.

Luke, R. (2011). Following a web design process. Smashing Magazine. 
Lynch, P. J., \& Horton, S. (2016). Web style guide: Foundations of user experience design. Yale University Press.

Mirdha, A., Jain, A., \& Shah, K. (2014). Comparative analysis of open source content management systems. Paper presented at the IEEE International Conference on Computational Intelligence and Computing Research. doi:10.1109/ICCIC.2014.7238337

Ojino, R., Mich, L., Ogao, P., \& Karume, S. (2013). The quality of Kenyan university websites: A study for the re-engineering of the Masinde Muliro university website. Journal of e-Learning. Knowledge in Society, 9(3), 169-176.

Organic Groups Module. (2020). Retrieved from https://www.drupal.org/project/og/

Owoyele, S. (2017). Website as a marketing communication tool. (Master of Science). Centria University of Applied Sciences.

Palwawankar, A. R. (2016). Content management system-Drupal in educational institute for teaching-learning. Asian Journal For Convergence In Technology, 2(3), 1-3.

Patel, S. K., Rathod, V., \& Prajapati, J. B. (2011). Performance analysis of content management systems-joomla, drupal and wordpress. International Journal of Computers and Applications, 21(4), 39-43. doi:10.5120/24963373

Rab, S. (2018). A university website using Content Management System (CMS) and add-on plugins (Master of Science). United International University.

Ray, A., \& Ramesh, D. (2017). Customization and embellishment of a library website using ABC theme of Drupal: A case study. Indian Journal of Science and Technology, 10(23), 1-10.

Rossi, G., Urbieta, M., Distante, D., Rivero, J. M., \& Firmenich, S. (2016). 25 years of model-driven web engineering. what we achieved, what is missing. CLEI Electronic Journal, 19(3), 5-57.

Runceanu, A., Popescu, M., \& Borcoși, I. (2013). How to build, develop, and maintain an educational website using an open source framework. Annals of Constantin Brancusi University of Targu-Jiu. Engineering Series, 1(3), 198-205.

Satish, S. (2014). Content management software-Drupal: Open source software to create library website. Paper presented at the International Conference on Library Space-Content Management for Networked Society.

Schimmel, K., Motley, D., Racic, S., Marco, G., \& Eschenfelder, M. (2010). The importance of university web pages in selecting a higher education institution. Research in Higher Education, 9, 1-16.

Simplesquare. (2017). Retrieved from https://simplesquare.com/

Suwawi, D. D. J., Darwiyanto, E., \& Rochmani, M. (2015). Evaluation of academic website using ISO/IEC 9126. Paper presented at the 3rd International Conference on Information and Communication Technology (ICoICT). doi:10.1109/ICoICT.2015.7231426

Taylor, A. (2011). Good website design-not just a pretty face. In Practice, 33(9), 486-489. doi:10.1136/inp.c4787

Tubin, D., \& Klein, S. (2007). Designing a school website: Contents, structure, and responsiveness. Planning and Changing, 38, 191-207.

UWE. (2020). UML-based Web Engineering. Retrieved from http://uwe.pst.ifi.lmu.de/

Views Module. (2020). Retrieved from https://www.drupal.org/project/views

The Web Modeling Language (WebML). (n.d.). Retrieved from http://webml.deib.polimi.it/page1.do.html

WordPress. (2020). Retrieved from https://wordpress.com

Yahaya, J. H., Ibrahim, A. A., \& Deraman, A. (2017). Software process model for dynamic website development towards quality product. Journal of Telecommunication, Electronic and Computer Engineering, 9(3), 39-44.

Zhang, T. (2017). The marketization of higher education discourse: A genre analysis of university website homepages in China. Higher Education Studies, 7(3), 64-79. doi:10.5539/hes.v7n3p64 